Ann. Geophys., 37, 1197-1222, 2019

https://doi.org/10.5194/angeo-37-1197-2019

(C) Author(s) 2019. This work is distributed under

the Creative Commons Attribution 4.0 License.

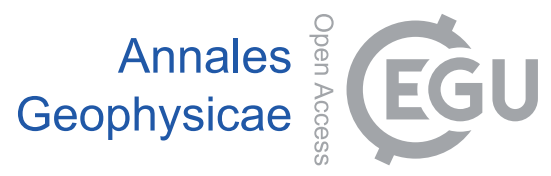

\title{
Terrestrial ion escape and relevant circulation in space
}

\author{
Masatoshi Yamauchi ${ }^{1, *}$ \\ ${ }^{1}$ Swedish Institute of Space Physics, Box 812, 98128 Kiruna, Sweden \\ * Invited contribution by Masatoshi Yamauchi, recipient of the EGU Julius Bartels Medal 2019.
}

Correspondence: Masatoshi Yamauchi (m.yamauchi@irf.se)

Received: 11 July 2019 - Discussion started: 12 July 2019

Revised: 31 October 2019 - Accepted: 19 November 2019 - Published: 19 December 2019

\begin{abstract}
Observations of the terrestrial ion escape to space and the transport of escaping ions in the magnetosphere are reviewed, with the main stress on subjects that were not covered in reviews over past 2 decades, during which Cluster has significantly improved our knowledge of them. Here, outflowing ions from the ionosphere are classified in terms of energy rather than location: (1) as cold ions refilling the plasmasphere faster than Jeans escape, (2) as cold supersonic ions such as the polar wind, and (3) as suprathermal ions energized by wave-particle interaction or parallel potential acceleration, mainly starting from cold supersonic ions. The majority of the suprathermal ions above the ionosphere become "hot" at high altitudes, with much higher velocity than the escape velocity even for heavy ions. This makes heavy hot ions more abundant in the magnetosphere than heavy ions transported by cold refilling ions or cold supersonic flow.

The immediate destination of these terrestrial ions varies from the plasmasphere, the inner magnetosphere including those entering the ionosphere in the other hemisphere and the tailward outer boundaries, the magnetotail, and the solar wind (magnetosheath, cusp, and plasma mantle). Due to time-variable return from the magnetotail, ions with different routes and energy meet in the inner magnetosphere, making it a zoo of different types of ions in both energy and energy distribution. While the mass-independent drift theory has successfully disentangled this zoo of ions, there are many poorly understood phenomena, e.g., mass-dependent energization. Half of the heavy ions in this zoo also finally escape to space, mainly due to magnetopause shadowing (overshooting of ion drift beyond the magnetopause) and charge exchange near the mirror altitude where the exospheric neutral density is at its highest.

The amount of heavy ions mixing directly with the solar wind is already the same as or larger than that entering into
\end{abstract}

the magnetotail and is large enough to extract the solar wind kinetic energy in the cusp-plasma mantle through the massloading effect and drive the current system near the cusp independently of the global current system. Considering the past solar and solar wind conditions, ion escape might even have influenced the evolution of the terrestrial biosphere.

\section{Introduction}

The circulation and roles of ionospheric heavy ions have long been an important subject in magnetospheric physics since they are found almost everywhere in the magnetosphere (Chappell, 1972; Shelley et al., 1972), including the highlatitude magnetosheath and plasma mantle (Lundin, 1985; Eklund et al., 1997). There are many studies on this problem, with many reviews, for example, on refilling and dynamics of the plasmaspheric cold ions (Darrouzet et al., 2009; Welling et al., 2015), the polar wind and cold supersonic ion outflow (Yau et al., 2007; Moore and Horwitz, 2007; André, 2015), the other outflow from the ionosphere to the magnetosphere (Moore et al., 1999a; Lotko, 2007; Maggiolo, 2015; Welling et al., 2015), and plasma sheet dynamics including energization in the magnetotail and resultant ring current ions in the inner magnetosphere (Blanc et al., 1999; Walker et al., 1999; Ebihara and Ejiri, 2003; Kronberg et al., 2014). However, very few reviews mention the total escape rate of the ionospheric ions to space (Moore and Horwitz, 2007; André, 2015), and no review discusses its quantitative importance for the atmospheric evolution, in contrast to the cases for Mars (Jakosky et al., 2015). To estimate this "ion budget" problem, two key subjects have been missing from the reviews during the past 2 decades: the outflowing ions directly accessing the solar wind in the magnetosheath, cusp, 
and outer part of the plasma mantle, and the fate of trapped hot ions that have much lower energy than the ordinary ring current, although a substantial amount of these ions will be lost to space (Dandouras et al., 2018).

The Cluster orbit and instrumentation allowed us to investigate these missing subjects with statistical significance, making it possible to synthesize these observations in the context of this ion budget problem. This paper synthesizes these missing parts that have been revealed by Cluster to obtain the ion escape rate to space and its consequences that have been overlooked in the past. Acceleration mechanisms for the outflowing ions such as wave-particle interactions (Lundin and Guglielmi, 2006), electrostatic fields and centrifugal acceleration (Cladis, 1986) are not covered in this paper, and hence the roles of electrons (e.g., Strangeway et al., 2005) are not discussed. Similarly, numerical simulations of $\mathrm{O}^{+}$tracing (e.g., Moore et al., 2014) are not covered.

Since the Cluster Ion Spectrometory COmposition DIstribution Function (CIS/CODIF) instrument is not designed to separate more than four main species $\mathrm{H}^{+}, \mathrm{He}^{++}, \mathrm{He}^{+}$, and atomic ions of the $\mathrm{CNO}$ group (Rème et al., 2001), all heavy ions are pedagogically called oxygen ions, $\mathrm{O}^{+}$, as is the usual convention, although nitrogen ions $\left(\mathrm{N}^{+}\right.$and $\mathrm{N}_{2}^{+}$) become significant during geomagnetic storms (Hamilton et al., 1988; Yau and Whalen, 1992). The paper is organized based on my Bartels Medal lecture at the EGU General Assembly 2019, as follows with the stress on Sects. 4 and 5.

1 Introduction

2 Ion outflow from the ionosphere

3 Destinations of the outflow

4 Inner magnetosphere at $L<6$ : zoo of many processes

5 Consequences of a large amount of $\operatorname{direct} \mathrm{O}^{+}$escape

6 Discussion

7 Conclusions

\section{Ion outflow from the ionosphere}

Outflows of ionospheric heavy ions are commonly observed at high latitudes (e.g., Moore et al., 1999a; André, 2015). These outflowing ions are often classified by the source location, but they can also be classified by the detection method: (1) cold filling to the plasmasphere (Park, 1974; Welling et al., 2015), (2) cold supersonic outflow to the inner magnetosphere and magnetotail such as polar wind (Su et al., 1998; Engwall et al., 2006, 2009), and (3) ions with suprathermal energy above the ionosphere (e.g., Eliasson et al., 1994) or with higher energy at higher altitude (e.g., Möbius et al., 1998). This paper follows this classification.

\subsection{Cold filling}

The cold filling flow along the magnetic field to the plasmasphere has long been implied from the time profile of the local plasmaspheric density with a drastic decrease during substorms and gradual recovery over days during quiet periods (Craven et al., 1997; Darrouzet et al., 2009; Sandel, 2011). In addition, continuous refilling of the plasmaspheric outward wind is also expected (Dandouras, 2013). Direct detection of refilling flow has been tried (Singh and Horwitz, 1992; Watanabe et al., 1992), using the distribution function method and an assumption of the same $\boldsymbol{E} \times \boldsymbol{B}$ drift velocity between different species to overcome the spacecraft potential. The estimated field-aligned flow velocities were less than $1 \mathrm{~km} \mathrm{~s}^{-1}$ (which means less than $0.02 \mathrm{eV}$ for $\mathrm{He}^{+}$), i.e., subsonic, while this could be underestimated (Shigeto Watanabe, personal communication, 2019), and this problem is still an open issue.

The refill rate has been estimated from the loss rate of the plasmaspheric ions for both sporadic plumes of $10^{27} \mathrm{~s}^{-1}$ for about $5 \%-10 \%$ of the time (Sandel and Denton, 2007; Darrouzet et al., 2008) and continuous loss of up to $5 \times$ $10^{26} \mathrm{~s}^{-1}$ (Dandouras, 2013), leading to a total rate of about $6 \times 10^{26} \mathrm{~s}^{-1}$. The composition is also estimated as $90 \%$ of thermal $\mathrm{H}^{+}$and $10 \%$ of $\mathrm{He}^{+}$, with only $1 \%-5 \%$ of $\mathrm{O}^{+}$ abundance (Darrouzet et al., 2009; Gallagher and Comfort, 2016). The abundance of $\mathrm{O}^{+}$in the refilling flux indicates that the process is much more effective than that of the Jeans escape. However, the refilling mechanism is not yet completely understood (Darrouzet et al., 2009; Gallagher and Comfort, 2016).

\subsection{Cold supersonic outflow}

The cold supersonic outflow here means the flow of ions with kinetic energy much higher than thermal energy but lower than the satellite potential when it is positive, i.e., inside dense plasma under sunlit conditions. For the Cluster case, active potential control did not help detect it (Sauvaud et al., 2004). In addition to the methods that are described in the previous subsection, Engwall et al. (2006) found a new method to obtain the bulk velocity and flux of this outflowing cold supersonic outflow in the lobe region where the density is very low. The obtained typical velocity is about $25 \mathrm{~km} \mathrm{~s}^{-1}$ $(3 \mathrm{eV})$ at $10-15 R_{\mathrm{E}}$ (Earth radius) from the Earth, as shown in Fig. 1 (Engwall et al., 2009). The increasing velocity with distance is consistent with centrifugal acceleration (Cladis, 1986) and with $10 \mathrm{~km} \mathrm{~s}^{-1}$ velocity at $>5000 \mathrm{~km}$ altitude in the dayside polar cap for $\mathrm{H}^{+}$(Abe et al., 1993; Su et al., 1998) and hence the polar wind (Pollock et al., 1990; Yau et al., 2007, and references therein). This flow increases with increases in F10.7 flux, solar wind dynamic pressure, Kp, and the southward interplanetary magnetic field, IMF $\left(B_{z}\right)$, in a manner consistent with DE-1 and Akebono observations (Yau et al., 2007, and references therein). 


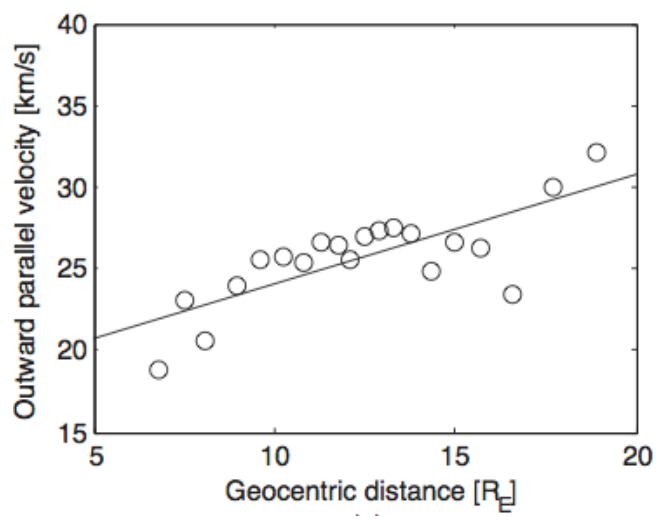

Figure 1. Altitude dependence of outward parallel velocity of cold supersonic flow observed by Cluster (Engwall et al., 2009).

The $\mathrm{O}^{+} / \mathrm{H}^{+}$density ratio decreases quickly with altitude, while the upward velocity ratio $\left(V_{\mathrm{O} \|} / V_{\mathrm{H} \|}\right)$ gradually increases toward unity with altitudes above $>5000 \mathrm{~km}$ (Abe et al., 1993; Yau et al., 2007). Slow $\mathrm{O}^{+}$stays at low altitudes longer and thus experiences the wave-particle interaction longer than fast $\mathrm{H}^{+}$, and low-frequency waves accelerate different species by the same velocity kick (Lundin and Guglielmi, 2006). Therefore, the velocity-filtered $\mathrm{O}^{+}$has a velocity similar to $\mathrm{H}^{+}$at higher altitudes, and a higher fraction of $\mathrm{O}^{+}$than $\mathrm{H}^{+}$becomes hot before it is convected to the lobe region.

\subsection{Suprathermal and hot outflows}

The last category (suprathermal ions and hot ions) is the one that can be directly detected by the ion instruments. In this paper, suprathermal ions and hot ions are not subdivided because the former are further accelerated to become the latter at $>6 R_{\mathrm{E}}$ distance (Lennartsson et al., 2004; Arvelius et al., 2005; Nilsson et al., 2006) or during travel to the other hemisphere (Cattell et al., 2002; Hultqvist, 2002; Yamauchi et al., 2005b). On the other hand, cold supersonic outflow and hot outflow are well separated in the magnetotail or plasma sheet according to the very few direct observations that identified both components (Olsen, 1992; Seki et al., 2003). The largest ionospheric sources of the suprathermal and hot ion outflows are around the dayside cusp and the nightside auroral oval (Moore et al., 1999a; Peterson et al., 2001).

For the dayside hot outflow, statistics at mid and high altitudes indicate that different species $\left(\mathrm{H}^{+}\right.$and $\left.\mathrm{O}^{+}\right)$are accelerated by the same velocity kick rather than by the same energy gain (Abe et al., 1993; Lennartsson et al., 2004; Nilsson et al., 2006). Polar apogee observations at $8 R_{\mathrm{E}}$, which is normally in the polar cap, showed a $V_{\mathrm{O} \|} / V_{\mathrm{H} \|}$ of about $0.3-0.6$ (Su et al., 1998), which is also larger than 0.25 , which corresponds to the same energy. The outflow flux is higher for $\mathrm{O}^{+}$ than $\mathrm{He}^{+}$(e.g., Abe et al., 1993), with a flux ratio $\left(F_{\mathrm{O}} / F_{\mathrm{H}}\right)$ of about 0.1 for the suprathermal energy range (thermal ion instrument for $<50 \mathrm{eV}$ ), and is close to 1 for the hot ion energy range of more than a few $\mathrm{eV}$ up to tens of $\mathrm{keV}$ (Moore et al., 1999a; Cully et al., 2003; Peterson et al., 2001; Sandhu et al., 2016). Unless the velocity-filter effect makes such a variation, all these observations indicate non-thermal energization mechanisms (Moore et al., 1999a; Lennartsson et al., 2004; Lundin and Guglielmi, 2006; Waara et al., 2011) such as wave-particle interaction (with a minor contribution by the centrifugal acceleration).

There is also one case study that observed the outflowing ions both before and after such accelerations, when the IMF was extremely dawnward. This condition shifted the northern cusp toward prenoon and the southern cusp toward postnoon, and hence the ion outflow from the southern cusp was detected as the ion inflow in the northern postnoon, well separated from the northern cusp signature, as shown in Fig. 2 (Yamauchi et al., 2005b).

While the outflowing energy from the northern cusp is similar between $\mathrm{O}^{+}$and $\mathrm{H}^{+}$, the energy ratio of inflowing $\mathrm{O}^{+}$and $\mathrm{H}^{+}$is nearly 15 when comparing the same location and about $\sim 20$ when comparing the energies of the most intense injections. Thus the ions are accelerated to the same velocity rather than the same energy in the magnetosphere even after considering the possible velocity-filter effect. Therefore, the energization of the dayside hot ion outflow at mid and high altitudes must be mainly by waves or other nonthermal processes. This applies even at low altitudes because the majority of the dayside outflowing ions at low altitudes are conic-like at low altitude rather than beam-like (Norqvist et al., 1996; Peterson et al., 2008).

On the other hand, a substantial portion of the nightside hot outflow from the auroral zone, for which the total amount is already 1 order less than the dayside outflow from around the cusp and prenoon auroral region (Peterson et al., 2001; Yau et al., 2007, and references therein), is in the beam form (Norqvist et al., 1998; Peterson et al., 2006) and is easier to return back to the ionosphere in the other hemisphere. For the velocity ratio, we expect $V_{\mathrm{O} \|} / V_{\mathrm{H} \|}=0.25$ after acceleration by the parallel electric potential and hence $\mathrm{O}^{+}$to move more downstream than $\mathrm{H}^{+}$compared to the mapping location along the geomagnetic field due to the velocity-filter effect.

\section{Destinations of the outflow}

This section describes the immediate destinations of the outflow but not the final destinations. Unlike above the ionosphere, cold ions in the magnetosphere have been observed by traditional hot ion instruments and hence on the very few occasions when the number density is high, for example, in the eclipse (Seki et al., 2003) and during bulk motion by Pc5 pulsation (Hirahara et al., 2004) or strong $\boldsymbol{E} \times \boldsymbol{B}$ drift (Sauvaud et al., 2001; Yamauchi et al., 2009a). 


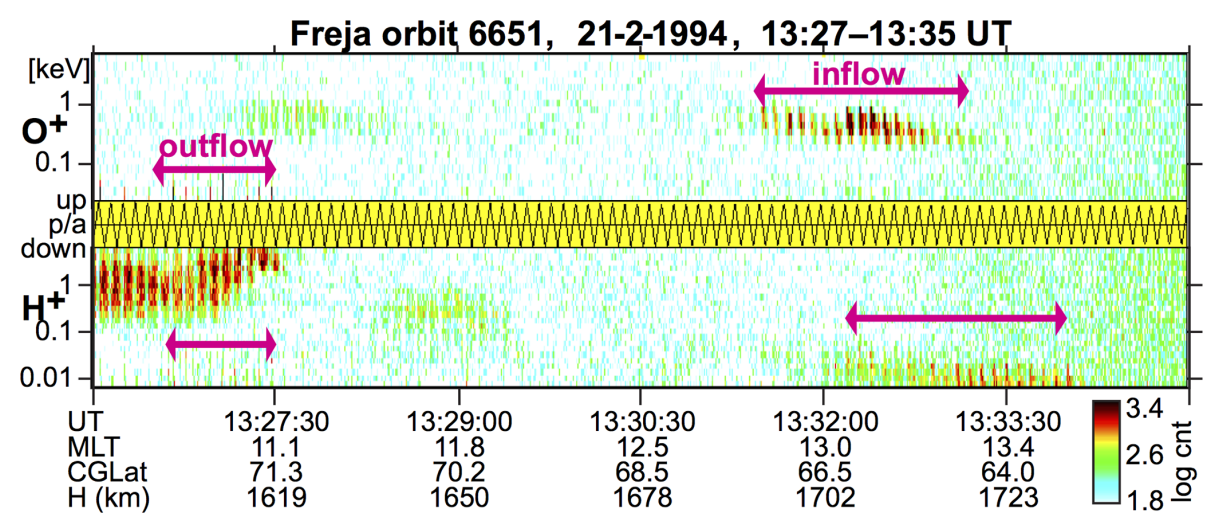

Figure 2. Energy-time spectrograms for heavy ions (marked as $\mathrm{O}^{+}$), protons, and electrons on 21 February 1994 observed by Freja in the dayside. Kp was $7+$ and the IMF $B_{Y}<-50 \mathrm{nT}$, which moved the northern cusp dawnward and southern cusp duskward (Yamauchi et al., 2005b).

\subsection{Cold filling to plasmasphere}

The destination of cold filling is mainly the plasmasphere as mentioned in Sect. 2.1. The refilling rate is estimated from the recovery of the plasmasphere after losing a massive amount of cold ions as plasmaspheric plumes (Sandel and Denton, 2007; Darrouzet et al., 2008) or outward wind (Dandouras, 2013) because they are most likely lost to space rather than returning.

\subsection{Known destination for cold supersonic outflow}

The destination of the cold supersonic outflow is not yet clear, except for the tail plasma sheet, because measurement is possible only in the low-density lobe region (Engwall et al., 2006; André, 2015). Engwall et al. (2009) derived the total flux flowing in the lobe and its Kp dependency and solar wind dependency. Their results can be scaled to roughly $3 \cdot \exp (0.23 \mathrm{Kp}) \times 10^{25} \mathrm{~s}^{-1}$ for $\mathrm{H}^{+}$, with a very low $(\leq 1 \%)$ $\mathrm{O}^{+} / \mathrm{H}^{+}$ratio.

In the lobe, the plasma convection across the geomagnetic field cannot be ignored compared to the outflow velocity, making the destination significantly different between species by the velocity-filter effect (Chappell et al., 1987) unless they are accelerated to the same velocity. Therefore, $\mathrm{O}^{+}$ is bent more toward the lower latitude than $\mathrm{H}^{+}$if they could reach the tail plasma sheet. This explains the recent observations of higher $\mathrm{O}^{+} / \mathrm{H}^{+}$flux ratios of trapped ions at lower energy and at lower geocentric distance in the inner magnetosphere (Claudepierre et al., 2016; Kistler and Mouikis, 2016) despite the low $\mathrm{O}^{+}$content in this flow, because adiabatic energization in the tail is larger for a more distant start point, i.e., larger for $\mathrm{H}^{+}$than $\mathrm{O}^{+}$if the destinations are different (Ejiri, 1978; Ebihara and Ejiri, 2003).

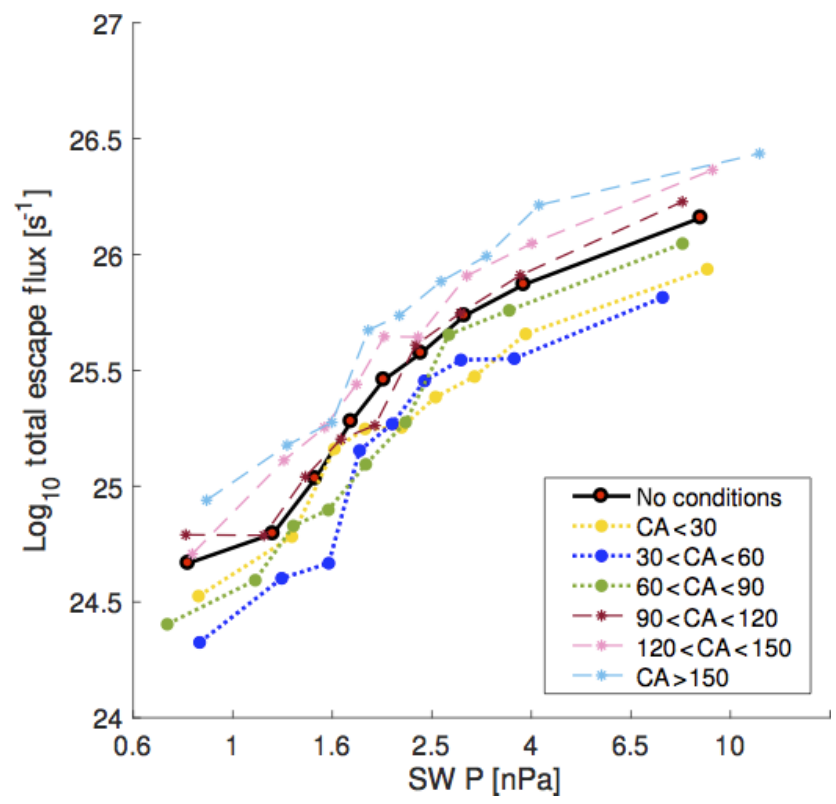

Figure 3. Cluster statistics of hot heavy ions' $\left(\mathrm{O}^{+}\right)$escape to space in the plasma mantle and magnetosheath. The total escape flux of the heavy ions is plotted as a function of the solar wind dynamic pressure for different IMF clock angles (CAs), which are defined as $0^{\circ}$ for the northward IMF (Schillings et al., 2019).

\subsection{Various destinations for hot outflow}

For the suprathermal and hot ions, the destination depends on the starting location and conditions in the ionosphere. Therefore, we consider the nightside outflow differently from the dayside outflow.

The dayside outflow has wide destinations, covering the tail plasma sheet, the plasma mantle, and even the magnetosheath (Shelley et al., 1972; Lundin, 1985; Eklund et al., 1997). Among these destinations, direct loss to space through the plasma mantle and magnetosheath was underes- 
timated before the Cluster observations, which showed that the amount is significant. The total hot $\mathrm{O}^{+}$flux into the plasma mantle and magnetosheath is as large as $10^{25-26} \mathrm{~s}^{-1}$ (Nilsson et al., 2012; Slapak et al., 2017a) and is larger than the total hot $\mathrm{O}^{+}$flux into the tail plasma sheet (Slapak et al., 2017b; Slapak and Nilsson, 2018). Geotail found mantle-like populations in the distant-tail plasma sheet beyond $-150 R_{\mathrm{E}}$ (Maezawa and Hori, 1998). They are flowing anti-sunward, suggesting that the heavy ions in the plasma mantle are generally lost to space.

The Cluster statistics of the solar (F10.7 flux), solar wind, and $\mathrm{Kp}$ dependences of these $\mathrm{O}^{+}$outflows in these regions show that solar wind dynamic pressure (Fig. 3), solar wind coupling function, and $\mathrm{Kp}$ are the most influencing parameters, with 1.5 orders of magnitude difference between quiet and active cases (Slapak et al., 2017a; Schillings et al., 2019). The IMF Bz dependence is not as drastic as the dependence of solar wind dynamic pressure, as shown in Fig. 3. These results are generally consistent with previous statistics of suprathermal or hot ion outflow at lower altitudes near the cusp (Moore et al., 1999a, b; Cully et al., 2003; Lennartsson et al., 2004).

However, Schillings et al. (2019) also found that the dependence on F10.7 flux is very weak. This is quite different from drastic F10.7 dependence of the suprathermal $\mathrm{O}^{+}$outflow at lower altitudes (Cully et al., 2003) or cold supersonic flow (Engwall et al., 2009). The difference indicates the following scenario: the extra acceleration by the wave-particle interaction and the wave activity reaching there does not depend on solar extreme ultraviolet (EUV) flux, but strongly on the solar wind's mechanical (dynamic pressure) and electric (coupling function) energies. Ions that received such acceleration may reach the exterior cusp and the plasma mantle before the velocity-filter effect bends them toward the nightside or low latitudes. In fact, the $\mathrm{X}$ flares enhance only the ion density and temperature without enhancement of ion outflow, which increases after the arrival of solar energetic particle events or coronal mass ejections (Yamauchi et al., 2018).

For the $\mathrm{O}^{+}$outflow from the nightside ionosphere, the majority of ion beams after being accelerated by the parallel electric potential drops are expected to re-enter the ionosphere in the opposite hemisphere as mentioned in Sect. 2.3. In fact, Freja at $1700 \mathrm{~km}$ altitude detected injecting ions with similar energy between $\mathrm{H}^{+}$and $\mathrm{O}^{+}\left(V_{\mathrm{O} \|} / V_{\mathrm{H} \|} \sim 4\right)$ in the $\mathrm{keV}$ range, suggesting that they are accelerated by parallel electric potential (Hultqvist, 2002). The observation also indicates the velocity-filter effect: the $\mathrm{O}^{+}$injection events are found mostly inside or equatorward of the $\mathrm{H}^{+}$injection events, ending up in what is traditionally called the central plasma sheet (CPS), a region of thermal unstructured electrons at several keV in range (Winningham et al., 1975; Woch and Lundin, 1993; Yamauchi et al., 2005b), making it difficult for $\mathrm{O}^{+}$to escape to space.

On the other hand, the majority of ion conics are expected to be trapped in the inner magnetosphere after mirror bounc- ing in the other hemisphere (Quinn and McIlwain, 1979). In fact, the inflow flux is much smaller than the outflow flux. Freja detected only about $50 \mathrm{O}^{+}$clear injection events over more than 5000 traversals over the auroral oval (Yamauchi et al., 2005b). For $\mathrm{H}^{+}$, statistics of DMSP at $840 \mathrm{~km}$ altitude of ion inflow (mainly $\mathrm{H}^{+}$) show 1-2 orders of magnitude smaller flux than outflow flux including the cusp (Moore et al., 1999a; Peterson et al., 2008; Newell et al., 2010), and this difference is larger in the nightside than dayside.

Polar observation at $6000-9000 \mathrm{~km}$ altitude during quiet periods shows that $30 \%$ of $\mathrm{O}^{+}$escape is from the noon quadrant, with $20 \%$ as ion beams and $50 \%$ as ion conics from the other quadrant (Peterson et al., 2006, 2008). Here, the total $\mathrm{O}^{+}$outflow flux drastically increases with altitude due to wave-related accelerations (Lennartsson et al., 2004; Arvelius et al., 2005; Waara et al., 2011), which is strongest near the cusp (Norqvist et al., 1998; Lennartsson et al., 2004). Furthermore, the dayside-nightside escape ratio increases with geomagnetic activities (Moore et al., 1999a). This makes the nightside contribution of $\mathrm{O}^{+}$outflow to the magnetosphere much smaller than that of the dayside. In fact, Cluster observation of the inner magnetosphere (see the next subsections) detected much higher fluxes of returning ions with drift signatures from the tail plasma sheet than directly entered ions. Therefore, we do not include the nightside source of the $\mathrm{O}^{+}$when considering the total escape that becomes important only during high geomagnetic activities. This route is marked as (b2) in Fig. 4.

\subsection{Secondary destinations from the near-Earth tail}

Major destinations of different types of outflowing ions are summarized in Fig. 4. A significant number of ions enters the tail plasma sheet (marked as c in Fig. 4) as the primary destination for both the cold supersonic outflow (Engwall et al., 2009; André, 2015) and the suprathermal/hot outflow (Sauvaud et al., 2004; Maggiolo and Kistler, 2014; Slapak et al., 2017b). This makes the plasma sheet a mixture of terrestrial ions and solar wind ions, with time-variable $\mathrm{O}^{+} / \mathrm{H}^{+}$ ratios and fluxes for terrestrial ions and relatively stable $\mathrm{He}^{++} / \mathrm{H}^{+}$ratios and fluxes for the solar wind (Lennartsson, 1997, 2001; Nosé et al., 2009). Some of these terrestrial ions keep flowing anti-sunward, particularly those which have large anti-sunward velocities along the geomagnetic field, either as continuous flow (Hirahara et al., 1996; Opitz et al., 2014) or as plasmoid (Christon et al., 1998; Kistler et al., 2010).

The rest of the terrestrial ions in this region return to the Earth mainly as either slow convection or bursty/sporadic flows (Ohtani et al., 2004; Slapak and Nilsson, 2018), with a higher $\mathrm{He}^{++} / \mathrm{O}^{+}$ratio than the anti-sunward flow that is lost to space (Lennartsson, 2001). Once the ionospheric ions enter the plasma sheet, they are energized by heating (Sergeev et al., 1993; Lennartsson, 1997; Kistler et al., 2005) and $\boldsymbol{J} \times \boldsymbol{B}$ force (Walker et al., 1999; Ohtani et al., 2004). 


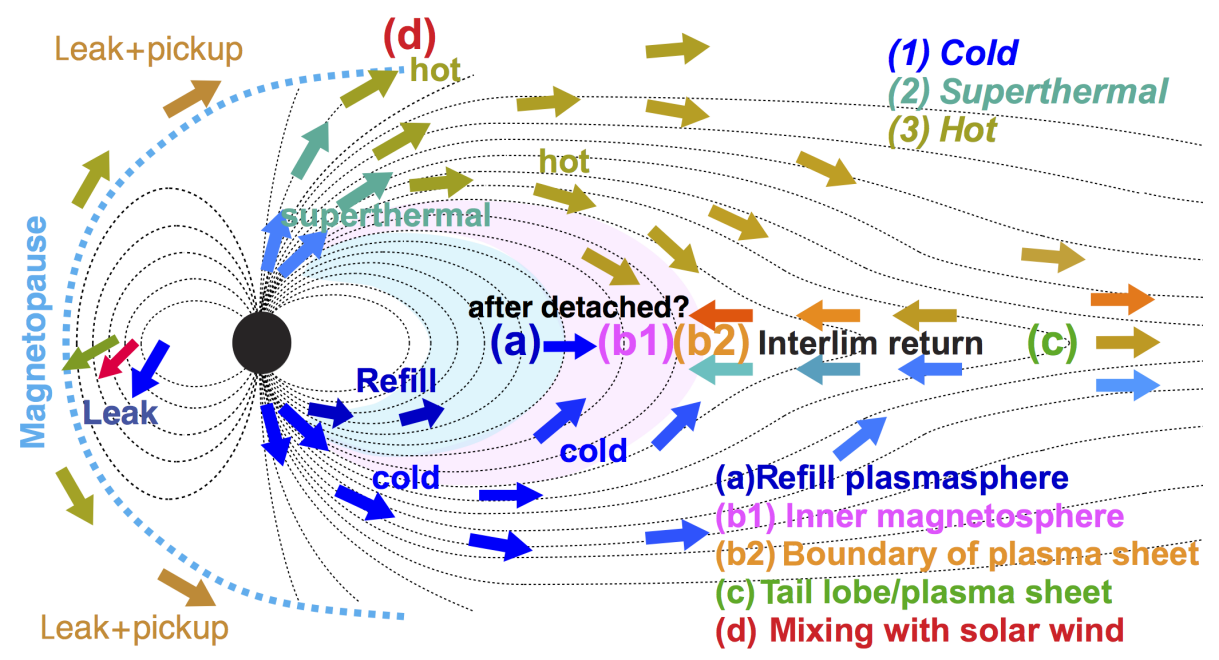

Figure 4. Summary of the destinations of ion outflow.

Even the cold ions are heated to $\sim 100 \mathrm{eV}$ according to both direct and indirect case studies (Seki et al., 2003; Ebihara et al., 2008). Ions returning to the Earth in the plasma sheet also undergo adiabatic energization as mentioned above. Thus, cold ions in the plasma sheet gain sufficient energy to be detected by hot ion instruments before they reach the earthward boundary of the magnetosphere, and returning ions from the tail plasma sheet are found at wide energy ranges at wide latitudes as shown in Fig. 5a. Nevertheless, it is possible to separate these two components in the inner magnetosphere because of different temporal variations between the cold source and hot source, as will be described in Sect. 4.3.

While the majority of returning $\mathrm{O}^{+}$enters the inner magnetosphere, some $\mathrm{O}^{+}$in the earthward boundary of the plasma sheet returns to the ionosphere (Hirahara et al., 1997; Sauvaud et al., 1999). The amount of the latter is small compared to the former because the majority of returning ions have finite pitch angles and hence can be ignored in estimating the total escape rate. Using Cluster hot ion composition data (covering $>28 \mathrm{eV}$ ), Slapak et al. (2017b) derived the total sunward (earthward) and anti-sunward fluxes in the plasma sheet at $X \sim-10 R_{\mathrm{E}}$ (they actually used the Cluster crossing between -20 and $-10 R_{\mathrm{E}}$ ), for both $\mathrm{H}^{+}$and $\mathrm{O}^{+}$, respectively. Slapak and Nilsson (2018) further examined $\mathrm{O}^{+}$flux in the lobe. The average net flux (budget) of hot $\mathrm{O}^{+}$in the nightside magnetosphere (lobe and plasma sheet) is $1 \times 10^{24} \mathrm{~s}^{-1}$ in the anti-sunward direction as a result of the high return rate $\left(6 \times 10^{24}\right.$ out of $7 \times 10^{24} \mathrm{~s}^{-1}$ anti-sunward flux). A complete result with $\mathrm{Kp}$ dependence is summarized in Table 1, where the average value corresponds approximately to $\mathrm{Kp}=3$, which gives the exponential factor in the table as about 3.3-3.9. The amount escaping through the tail plasma sheet is 1 order of magnitude smaller than that through the plasma mantle and magnetosheath (Slapak et al., 2017a; Schillings et al., 2019).
The Cluster result of the $\mathrm{O}^{+}$return flux near the Earth is smaller than the indirect "guess" by Seki et al. (2001), who estimated the return flux from the decrease in anti-sunward hot ion flux with distance using Geotail. In addition to Geotail's orbital limitation to the equator that barely covers the largest escape route established by Cluster, the upper energy limit in their study was only $17 \mathrm{keV}$, whereas the escaping $\mathrm{O}^{+}$has a wide energy range around the solar wind speed $\left(450 \mathrm{~km} \mathrm{~s}^{-1}\right.$ for $\left.17 \mathrm{keV} \mathrm{O}^{+}\right)$in the distant tail, as was demonstrated for the downstream of Venus (Grünwaldt et al., 1997). Thus their study missed the majority of $\mathrm{O}^{+}$escape flux during fast solar wind conditions, i.e., when the escape flux is high (Schillings et al., 2017, 2019).

The return flow flux compared to detectable anti-sunward flow in the plasma sheet is much smaller for $\mathrm{H}^{+}$(earthward $1.3 \times 10^{26} \mathrm{~s}^{-1}$ with anti-sunward $5 \times 10^{25} \mathrm{~s}^{-1}$ in the visible energy range) than $\mathrm{O}^{+}$(Lennartsson, 2001; Slapak et al., 2017b), supporting the assumption of an extremely low $\mathrm{O}^{+} / \mathrm{H}^{+}$ratio for the hidden cold supersonic flow. In other words, we may safely ignore $\mathrm{O}^{+}$in the cold supersonic flow into the plasma sheet when discussing the total amount of escape and return, although Slapak et al. (2017b) and Slapak and Nilsson (2018) could not include such hidden flow (covering $\mathrm{O}^{+}$with a returning velocity of $>60 \mathrm{~km} \mathrm{~s}^{-1}$ only).

\section{Inner magnetosphere at $L<6$ : zoo of many processes}

As illustrated in Fig. 4, all types of outflow may enter the inner magnetosphere directly or indirectly, making the inner magnetosphere a mixture of ions from different sources. Among these, ion population and dynamics in the inner magnetosphere with only one or two sources have long been studied, with good reviews for cold plasmaspheric ions (Darrouzet et al., 2009), ordinary ring current ions at $>10 \mathrm{keV}$ 
Table 1. Major outflow destinations and flux of $\mathrm{O}^{+}$observed by Cluster.

\begin{tabular}{lllrrl}
\hline primary destination & Fig. 4 & energy & average $\left(\times 10^{25} \mathrm{~s}^{-1}\right)$ & range $\left(\times 10^{25} \mathrm{~s}^{-1}\right)$ & escape? \\
\hline magnetosheath & $\mathrm{d}$ & $0.03-40 \mathrm{keV}^{\mathrm{a}}$ & 0.7 & $0.14 \exp (0.45 \mathrm{Kp})$ & all \\
plasma mantle & $\mathrm{d}$ & $0.03-40 \mathrm{keV}^{\mathrm{a}}$ & 2 & $0.82 \exp (0.45 \mathrm{Kp})$ & mostly \\
lobe & $\mathrm{c}$ & $0.03-40 \mathrm{keV}^{\mathrm{b}}$ & 0.3 & $0.07 \exp (0.43 \mathrm{Kp})$ & $>$ half \\
lobe & $\mathrm{c}$ & supersonic & $<0.1$ & $<0.03 \exp (0.23 \mathrm{Kp})$ & $>$ half \\
magnetotail (tailward) & $\mathrm{c}$ & $0.03-40 \mathrm{keV}^{\mathrm{b}}$ & 0.5 & $0.15 \exp (0.40 \mathrm{Kp})$ & all \\
magnetotail (earthward) & $\mathrm{c}$ & $0.03-40 \mathrm{keV}^{\mathrm{b}}$ & 0.6 & $0.18 \exp (0.42 \mathrm{Kp})$ & half \\
boundary plasma sheet & $\mathrm{b} 2$ & $0.03-40 \mathrm{keV}^{\mathrm{n}}$ & small & & $<$ half \\
inner magnetosphere & $\mathrm{b} 1$ & $<10 \mathrm{keV}$ & small & & half \\
plasmasphere & $\mathrm{a}$ & cold & $<2^{\mathrm{d}}$ & & mostly \\
\hline
\end{tabular}

${ }^{\text {a }}$ Slapak et al. (2017a), ${ }^{\mathrm{b}}$ Slapak and Nilsson (2018), ${ }^{\mathrm{c}}$ Engwall et al. (2009), ${ }^{\mathrm{d}}$ assuming $\sim 3 \%$ abundance (no direct $\mathrm{O}^{+}$observations).

(Daglis et al., 1999), radiation belts (Blanc et al., 1999), and theories (Ebihara and Ejiri, 2003; Kronberg et al., 2014). However, sources and dynamics of hot sub-keV ions were much less understood, partly because ions in this energy range have many different sources.

The hot ion source is not only from the plasma sheet, but can also be directly supplied from the ionosphere, as mentioned in Sect. 3.3. Horwitz and Chappell (1979) found field-aligned "warm" ions of about $10 \mathrm{eV}$ temperature with small bulk velocity in the inner magnetosphere, and its hightemperature cases are also observed by Cluster (Yamauchi et al., 2013). Local heating of the cold ions, particularly in the equatorial plane, can also produce hot ions from the cold plasmaspheric ions (Olsen et al., 1987). Combined together, the inner magnetosphere becomes rich in various types of sub-keV ions (Yamauchi et al., 2013). Figure 5 shows typical Cluster observations at different magnetic local times (MLT). Thank to Cluster's quick traversal near the perigee (about $4 R_{\mathrm{E}}$ ) along the same longitude in a symmetric manner during 2001-2006, one can organize the data as a latitudeenergy pattern. However, the sub-keV ion data are still complicated and vary significantly with local time.

This is one of the reasons why the formation mechanisms of these sub-keV ions in the inner magnetosphere have not been well studied before Cluster, particularly at $L<6$ ( $L$ is the equatorial distance in $R_{\mathrm{E}}$ when mapped along the geomagnetic field), although many magnetospheric missions 50-30 years ago had already detected these ions (Sauvaud et al., 1981; Chappell et al., 1982, 2008; Newell and Meng, 1986; Yamauchi et al., 2005a, 2013, and references therein). This section mainly reviews this energy range for which Cluster significantly improved our knowledge. Accordingly, "inner magnetosphere" means $L<6$ (or invariant latitude $\left(\right.$ Inv) $<65^{\circ}$ ) in this section. For the other phenomena, readers may refer to other review papers that are listed in the introduction.

\subsection{Energy dependency of ion drift}

To deconvolve different sources and mechanisms, prediction of morphologies from all the known sources using ion drift simulation is useful because ion motions in the inner magnetosphere are, thanks to the strong geomagnetic field, basically dominated by magnetic (gradient- $B$ and curvature) drift and the $\boldsymbol{E} \times \boldsymbol{B}$ drift. The magnetic drift (velocity $V_{B}$ ) moves ions westward nearly steadily and is energy dependent. For ion energy $(W)$ in a dipole field (strength at equator $B$ ), it is approximately

$V_{B} \propto \frac{g(\alpha) \cdot W}{B \cdot L}$,

where the factor $g(\alpha)$ is 2 for pitch angle $\alpha=0^{\circ}$ and 3 for $\alpha=90^{\circ}$.

The $\boldsymbol{E} \times \boldsymbol{B}$ drift varies in time, although it is energy independent, with its velocity $\left(V_{E}\right)$ proportional to $E / B$, where $E=E(t)$ is the electric field component perpendicular to the magnetic field. The $\boldsymbol{E} \times \boldsymbol{B}$ drift moves ions eastward during quiet time (co-rotation), but a sunward drift component (westward in the dusk and eastward in the dawn) is added by an externally driven dawn-to-dusk electric field during active periods. This motion is dominant for cold plasmaspheric ions that have zero magnetic drift velocity (Goldstein, 2006; Darrouzet et al., 2008). Both drifts are mass independent; i.e., the drift velocity is the same if the energy is the same.

Adding both the magnetic and $\boldsymbol{E} \times \boldsymbol{B}$ drifts, westward ion drift is expected for high energy (generally $>20 \mathrm{keV}$; the socalled ring current) or in the evening sector, and eastward for low energy (generally $>5 \mathrm{keV}$ ) and in the morning sector. The combination of these drifts also adiabatically energizes ions through the conservation of the adiabatic invariant as

$$
\frac{W}{W_{0}}=\left(\frac{L}{L_{0}}\right)^{-g(\alpha)}
$$

where suffix 0 denotes the initial energy and location (Ejiri, 1978). Assuming a dipole field $\left(B \propto L^{-3}\right), V_{B}$ is larger for larger $L$, particularly for high $\alpha$. 


\section{Cluster (SC-4) CIS/CODIF data}
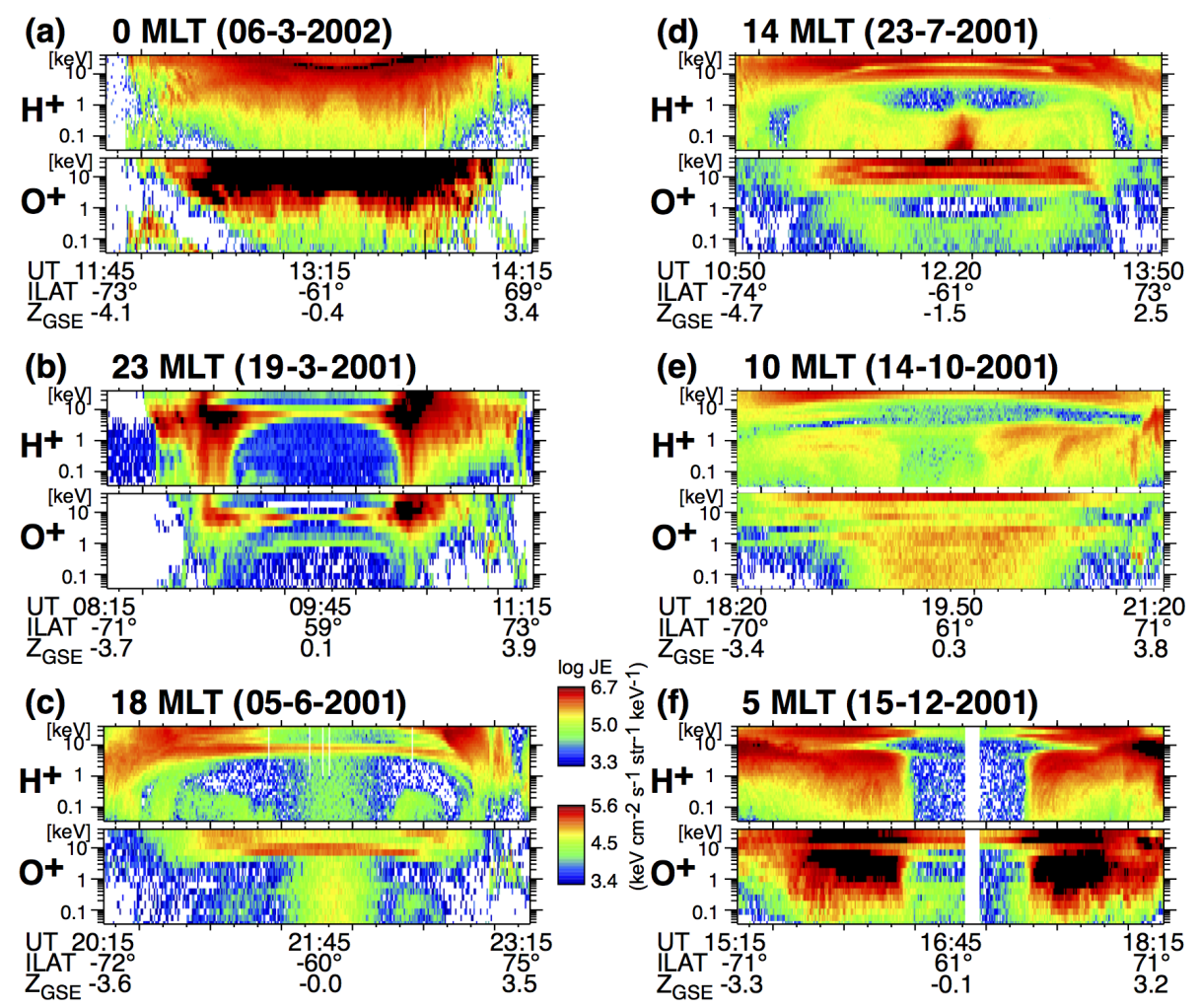

Figure 5. Cluster examples of the energy-time spectrograms of hot ion differential energy fluxes $\left(\mathrm{keV} \mathrm{cm}^{-2} \mathrm{~s}^{-1} \mathrm{sr}^{-1} \mathrm{keV}^{-1}\right)$ at different local times in the inner magnetosphere before and after its perigee (nearly $4 R_{\mathrm{E}}$ ). The heavy ions (marked as $\mathrm{O}^{+}$) eventually include all CNO group ions. Orbits during these observations are nearly north-south symmetric along nearly the same local time starting from the Southern Hemisphere.

Using a simple dipole field and a dawn-dusk symmetric electric field, Ejiri et al. (1980) simulated the drift motion starting from $10 R_{\mathrm{E}}$ and re-constructed the energy- $L$ spectrogram of virtual satellite observation over $L=2-6$ for both ions and electrons. In their simulation, nose-like diminishing of the westward-drifting $\mathrm{keV}$ ions toward the lower latitude (nose structure) and the boundary of the forbidden region for the eastward-drifting ions are qualitatively reproduced at 5$10 \mathrm{~h}$ after the start of injection. Examples of the nose structure are shown in Fig. $5 \mathrm{~b}$ and $\mathrm{c}\left(\mathrm{H}^{+} 10 \mathrm{keV}\right.$ band), and examples of forbidden regions are shown in Fig. $5 \mathrm{~d}-\mathrm{f}(<5 \mathrm{keV}$ ions).

At the energy between the westward and eastward drift regimes, we expect no ion population (Jordanova et al., 1999), as has been observed (Collin et al., 1993; Kovrazhkin et al., 1999). This "gap" energy is estimated by setting the ratio of azimuthal $(\phi)$ drift velocities

$\left(\frac{V_{E}}{V_{B}}\right)_{\phi} \sim \frac{6.6 \cdot L \cdot E_{\mathrm{r}}\left[\mathrm{mV} \mathrm{m}^{-1}\right]}{g(\alpha) \cdot W[\mathrm{keV}]}$

as unity, where $E_{\mathrm{r}}$ is the radial (duskward in the dawn sector) electric field (Yamauchi et al., 2006a). To have a new injection from the magnetotail, we need a duskward external electric field, during which the inward electric field $-E_{\mathrm{r}}$ and hence $W_{\text {gap }}$ decrease with increasing local time starting from the dusk sector, as seen in Fig. 5. Such a local-time dependence is statistically confirmed by Viking and Cluster (Yamauchi and Lundin, 2006; Yamauchi et al., 2006a).

\subsection{Dynamics of cold plasmaspheric ions}

For plasmaspheric dynamics, readers may refer to the review by Darrouzet et al. (2009). Here are some extra notes from the viewpoint of the drift motion of hot but low-energy ions $(<100 \mathrm{eV})$. Since the magnetic drift velocity is zero for cold ions, the majority of the plasmaspheric ions move according to time-dependent $\boldsymbol{E} \times \boldsymbol{B}$ drift which is a summation of convection by the external electric field and the corotation. A sudden enhancement of the duskward external electric field adds an inward motion in the midnight sector and outward motion in the noon sector. As a result of such a pumping force, the plasmasphere is eroded in the nightside and plume is formed in the dayside, as was reported half a century ago. However, overall plasmaspheric dynamics (including erosion, plume formation, its detachment, and even 
CIS/CODIF data (SC-4) , 3-1-2002
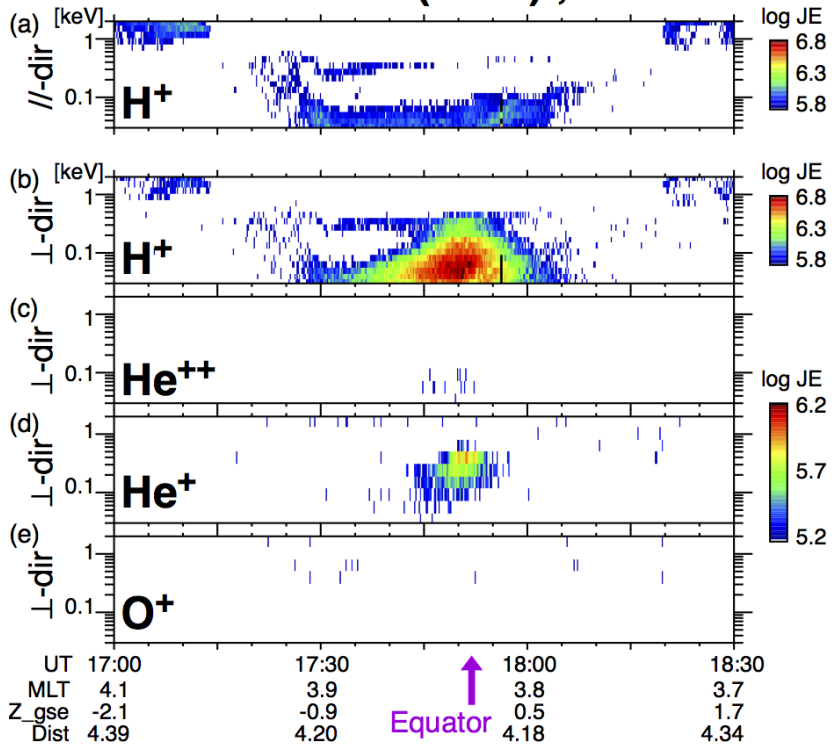

Figure 6. Cluster hot ion energy-time spectrograms of differential energy fluxes $\left(\mathrm{keV} \mathrm{cm}^{-2} \mathrm{~s}^{-1} \mathrm{sr}^{-1} \mathrm{keV}^{-1}\right)$ during perigee traversal on 3 January 2002 (Yamauchi et al., 2012). The most field-aligned sector and the most perpendicular sectors to the geomagnetic field are plotted. The vertical arrow at the bottom indicates the crossing of the equatorial plane that is identified by the wave activity observed by WHISPER.

smaller structures) had not been synthesized until the IMAGE FUV instrument succeeded in taking a "photograph" of the plasmaspheric $\mathrm{He}^{+}$(Goldstein, 2006). The detachment starts near noon, with the outer part reaching the magnetopause and escaping to the magnetosheath (called magnetopause shadowing as described in Sect. 4.7) in the entire afternoon sector, as is also confirmed with the ion data and plasma wave data (Sauvaud et al., 2001; Darrouzet et al., 2008), while the rest of the plume might detach in the nightside. This agrees with the local time dependence of the demarcation energy between westward drift and eastward drift as mentioned above. The cold ion density at the magnetopause can be as high as $>100 \mathrm{~cm}^{-3}$ during quiet periods (Sauvaud et al., 2001).

In addition to these cold ion convections, ions are often heated in the perpendicular direction to the magnetic field near the equatorial plasmapause within a few degrees of the latitudinal range (Olsen et al., 1987). These equatorially trapped warm ions are observed during nearly all geomagnetic conditions and are mainly found at $<5 R_{\mathrm{E}}$ at all local times, i.e., in the outer part of the plasmasphere (Darrouzet et al., 2009). The development time is estimated as about $1 \mathrm{~h}$, but it decays before drifting over a few hours in local time. Figure 6 shows one such example observed by Cluster (Yamauchi et al., 2012). Just limited to the geocentric distance that Cluster traversed $\left(4.0-4.5 R_{\mathrm{E}}\right.$ at the equa- (a) 20 MLT Cluster (CIS-4), 04-5-2004

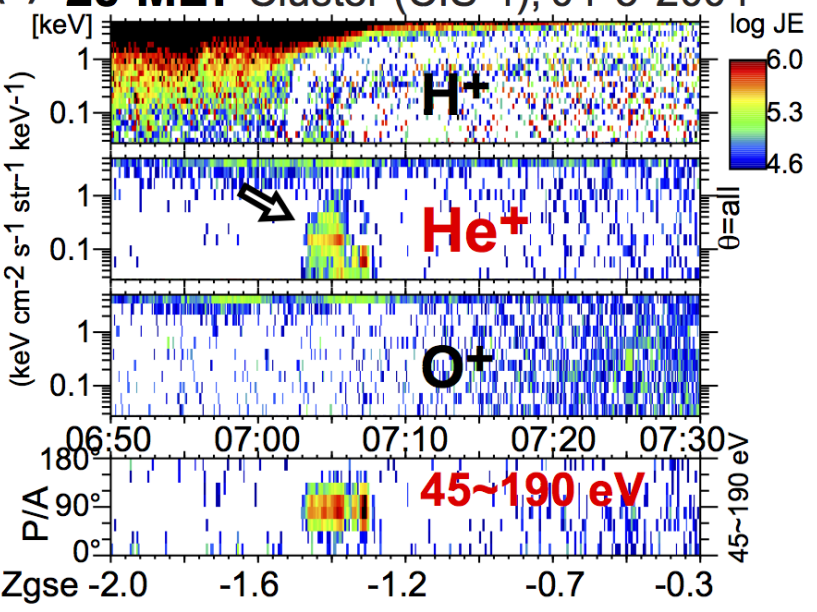

(b) 21 MLT Cluster (CIS-4), 30-4-2005

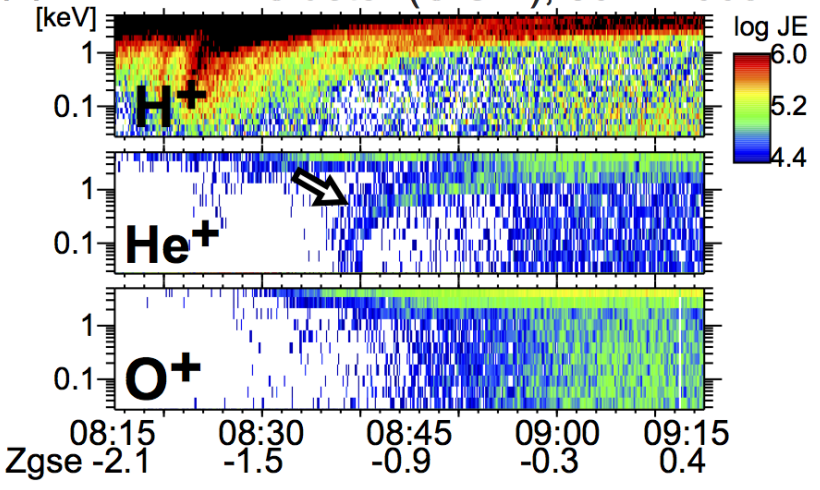

Figure 7. Cluster hot ion observation of $\mathrm{He}^{+}$that shows different energy-time features from those of $\mathrm{H}^{+}$and $\mathrm{O}^{+}$. The unit of the differential energy fluxes (JE) is $\mathrm{keV} \mathrm{cm}^{-2} \mathrm{~s}^{-1} \mathrm{sr}^{-1} \mathrm{keV}^{-1}$. (a) 4 May 2004 and (b) 30 April 2005 (Yamauchi et al., 2014a). For the first event, the energy-pitch angle spectrogram is also displayed.

tor) and to ions more than $30 \mathrm{eV}$ (strong heating), these ions are found in nearly half the noon-dusk traversals during solar maximum, while the probability is slightly lower in the night-dawn traversals because these ions are normally found at shorter geocentric distances there. The upper energy is normally $<100 \mathrm{eV}$ for $\mathrm{H}^{+}$and $<500 \mathrm{eV}$ for $\mathrm{He}^{+}$, with a variable $\mathrm{He}^{+} / \mathrm{H}^{+}$ratio for both energy (1-5) and density $(0 \%-$ $10 \%$ ). In Fig. 6, both $\mathrm{He}^{+}$and $\mathrm{H}^{+}$show a ring distribution with nearly $90^{\circ}$ pitch angles, while a simple pancake distribution with nearly $90^{\circ}$ pitch angles is more commonly observed, particularly for $\mathrm{H}^{+}$, indicating that more than one energization mechanism are involved. The wave modes that are responsible for such energization have not been identified.

Local perpendicular heating is not limited to the equator. Cluster also observed perpendicular $\mathrm{He}^{+}$heating (without $\mathrm{H}^{+}$heating) away from the equator, although it is rare. Figure 7a shows an example (Yamauchi et al., 2014a). The lo- 
cation and the occurrence frequency suggest that the wave mode related to this heating is different from the perpendicular heating near the equator. The absence of $\mathrm{H}^{+}$strongly suggests a mass-dependent resonance frequency, although the associated wave mode has again not been identified.

\subsection{Dynamics of hot ions injected from the tail plasma sheet}

Before examining outflowing ions reaching directly from the ionosphere to the inner magnetosphere, we consider ions injected from the tail plasma sheet (marked as c in Fig. 4), where both cold and hot components co-exist as described in Sect. 3. The basic motion of these injected ions is described in Sect. 4.1, and the $L$ dependence of the drift velocity for both magnetic and $\boldsymbol{E} \times \boldsymbol{B}$ drifts through the strength and curvature of the magnetic field (cf. Eq. 3 for part of this $L$ dependence) causes the energy-latitude dispersions as shown in Fig. 5. The actual direction of the drift (westward or eastward) depends on the start energy and the start location, because the degree of adiabatic energization depends on the start location in both the dawn-dusk $(Y)$ direction and the anti-sunward $(-X)$ direction (Ejiri, 1978; Ebihara and Ejiri, 2003). For example, the same energy of the ions in the tail may cause a wide energy range of injected ions at the edge of the inner magnetosphere ( $L=6$ in the paper) depending on the start location, and this energy determines the drift direction either westward or eastward.

The externally driven electric field varies much faster than the drift time over a few hours in local time, making the injection time-variable. This situation can be approximated by multiple injections. Since higher-energy ions have higher magnetic drift velocities on the same $L$ shell, these higherenergy ions arriving at the same $L$ shell overtake previously arrived lower-energy ions. The local time of such overtaking depends on $L$ and the electric field. The multiple band at the same $L$ shell can also be formed if the westward drift of high-energy ions $(>10 \mathrm{keV})$ is fast enough to make more than one round of the Earth before decaying (e.g., during major magnetic storms), but this does not happen as often as for electrons that drift around the Earth much faster than ions. Multiple bands of westward-drifting ions are indeed observed (Buzulukova et al., 2002; Ebihara et al., 2004; Vallat et al., 2007), like Fig. 5b-d at around 10 and above $30 \mathrm{keV}$.

The energy (latitude) of these bands can be different between different species because the start location of ionospheric ions in the tail plasma sheet can be different between different species when the lobe convection is strong as mentioned in Sect. 3.2. Figure 7b shows one such example. However, the majority of observations show the same energylatitude dispersion (same energy at the same $L$ ) between different species, indicating that the start location (density distribution) in the tail plasma sheet is similar between different species and hence that the destination of outflowing ions into the plasma sheet is similar between different species with-

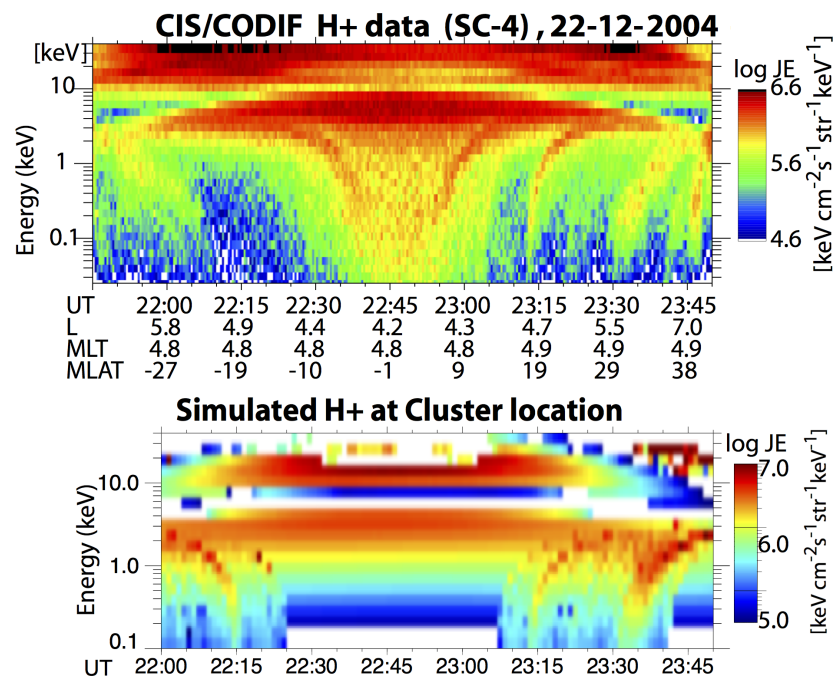

Figure 8. Energy-time spectrograms of ion differential energy flux during perigee traversal of Cluster SC-4 on 22 December 2004 and reconstruction of the energy-time spectrogram by particle drift simulation (Yamauchi et al., 2009a). The simulation shows dual populations ("sub-keV" and "hot" components) with the sub-keV component varying in time much more than the hot component. The ion signatures that are not reconstructed have different sources from the tail plasma sheet (see text).

out velocity-filter effects. This is reasonable for suprathermal and hot outflow because parallel velocity is similar between different species as mentioned in Sect. 2.3. For the cold supersonic flow, no direct observation exists to examine these indications, and we need future observations.

Contrary to westward-drifting ions, eastward-drifting ions occupy a rather wide energy range because the $\boldsymbol{E} \times \boldsymbol{B}$ drift is energy independent. Since the externally driven electric field varies with timescales shorter than the drifting timescale as mentioned above, the morphology of eastward-drifting ions significantly varies in time. As a result, the demarcation energy depends strongly on the external electric field and hence the substorm activity. For severe substorms, even ions $>40 \mathrm{keV}$ may drift eastward at $L=4-5$ (Yamauchi et al., 2009a).

Overlaying these band structures, we sometimes see vertical stripes with wedge-like energy-latitude dispersions at energies below the westward-drifting band in energytime spectrograms ("wedge-like structure"), such as Fig. 8a. These vertical stripes with dispersions are found mainly from the midnight to morning sectors, with smaller dispersion closer to the local midnight, as in Fig. 5a. Sometimes, the westward-drifting band also ends with a similar wedge-like structure to these stripes, particularly in the noon to afternoon sectors, as in Fig. 5d.

In observations, there are three different dispersion patterns of these wedge-like structures (Ebihara et al., 2001; Yamauchi et al., 2005a): increasing energy with $L$, as in Figs. 5e 


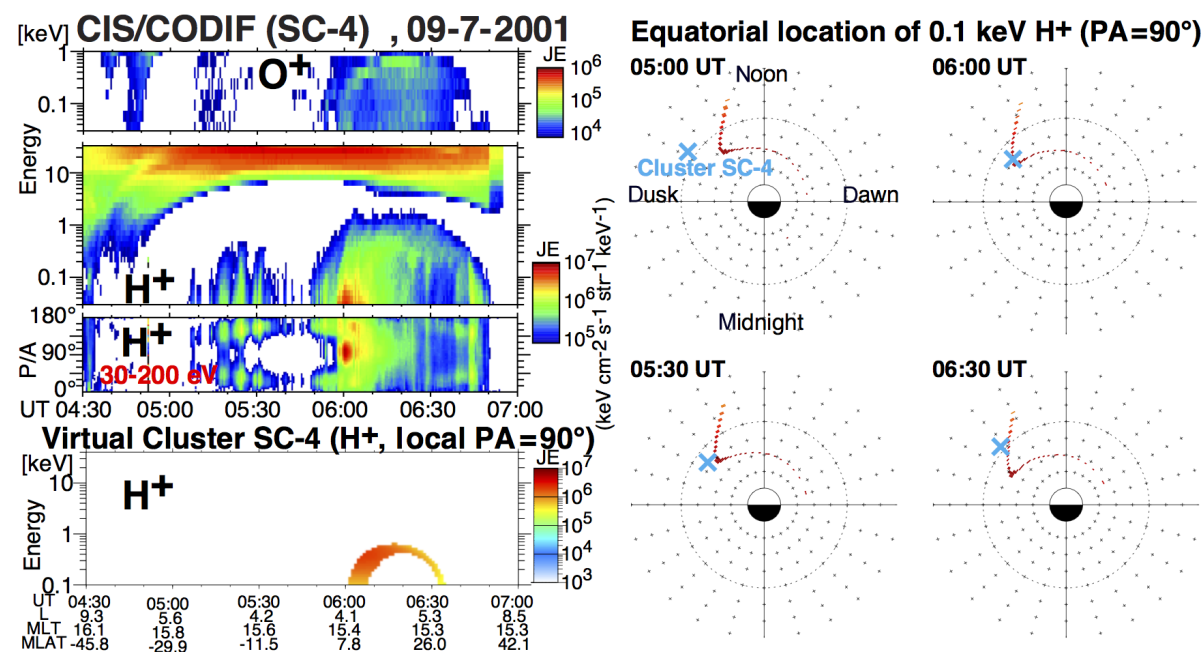

Figure 9. Cluster CODIF perigee observation on 9 July 2001 and its ion drift simulation using the Volland-Stern electric field model (Yamauchi et al., 2014b). Three types of sub-keV ions (eastward-drifting energy range) are convoluted in the ion data: (i) recently injected nearly field-aligned suprathermal ions during 05:15-05:35 UT, (ii) equatorially trapped perpendicularly heated plasmaspheric ions at 05:5906:02 UT, and (iii) arch-like dispersed ions during 05:50-06:50 UT. The first one was observed at similar timings between SC-4 and SC-3, whereas the second one was observed at the local equator that is $30 \mathrm{~min}$ apart between SC-4 and SC-3. The simulation in the bottom-left panel reproduced only the last type. Locations of the simulated $0.1 \mathrm{keV} \mathrm{H}^{+}$and Cluster are shown in the four images on the right.

and 8, decreasing energy with $L$, as in Fig. 5d, and first increasing and then decreasing energy with $L$, as in Fig. 5c. Since the electric field in the inner magnetosphere can be modeled (Ebihara and Ejiri, 2003, and references therein), one can even estimate the energy distribution at a specific boundary (e.g., $8-10 R_{\mathrm{E}}$, where the azimuthal drift starts) using backward phase-space mapping. The estimated energy distributions have successfully reproduced all three dispersion patterns by the forward ion drift simulation (Ebihara et al., 2001).

Even a single simulation can reproduce three different drift components at different energies (westward-drifting band above the energy gap, eastward-drifting band below the energy gap, and sub-keV stripes at lower energies), as shown in Fig. $8 \mathrm{~b}$. The simulation suggests that both the eastward and westward bands originate from a hot component in the nearEarth, with wide start locations in $Y$, whereas the sub-keV stripes most likely originate from "warm" ions $<100 \mathrm{eV}$, i.e., ions supplied as cold supersonic flow as mentioned in Sect. 3 (Ebihara et al., 2008; Yamauchi et al., 2009a). The duration of each stripe corresponds to that of the supply of these warm ions. The result suggests that the flux or the destination $(X$ distance) to the tail plasma sheet of the cold supersonic outflow varies significantly.

For example, the start of the sunward convection after southward turning of the IMF predicts a sudden appearance of such "sub-keV stripes" of warm ion origin in the inner magnetosphere. The Cluster orbit allows us to detect such an appearance as inbound-outbound asymmetry, as shown in Fig. 9. The sub-keV ions that suddenly appeared after the equatorial perpendicular heating at 06:00-06:02 UT
(Sect. 4.2) are successfully reproduced as a result of a warm source, using the same simulation method as Fig. 8. The repeated $\mathrm{H}^{+}$bursts from 05:07 to 05:55 UT that are not reproduced have lower pitch angles, and hence they must have a different source, i.e., directly from the ionosphere, as will be discussed in the next subsection.

Considering the velocity-filter effect of drifting ions, a satellite that slowly traverses the inner magnetosphere can also detect the time-of-flight effect of eastward drift because of the energy dependency of the drift velocity. This effect is seen in Fig. 10 (Yamauchi et al., 2006a). After extracting the temporal variation on the same $L$ shell using the differences between three spacecraft and combining the observed electric field and average drift velocity, the elapsed time of the suddenly appearing hot $\mathrm{H}^{+}$at $0.1-10 \mathrm{keV}$ is estimated as only 15-30 min (substorm onset was about $30 \mathrm{~min}$ before) after the start of the dispersion with a start local time at around 6-8 MLT.

Thus, dispersion may start in the dawn sector instead of the midnight sector, as illustrated in Fig. 10h. This indicates that the electric field in the midnight-dawn sector can be stronger than was previously thought, particularly for severe substorms. Such a strong electric field is also suggested by the high demarcation energy of $>40 \mathrm{keV}$ as mentioned above and is theoretically possible when it is highly screwed.

\subsection{Dynamics of outflowing ions directly supplied from the ionosphere}

As mentioned in Sect. 3, some outflowing ions from the ionosphere enter the inner magnetosphere directly inside the 


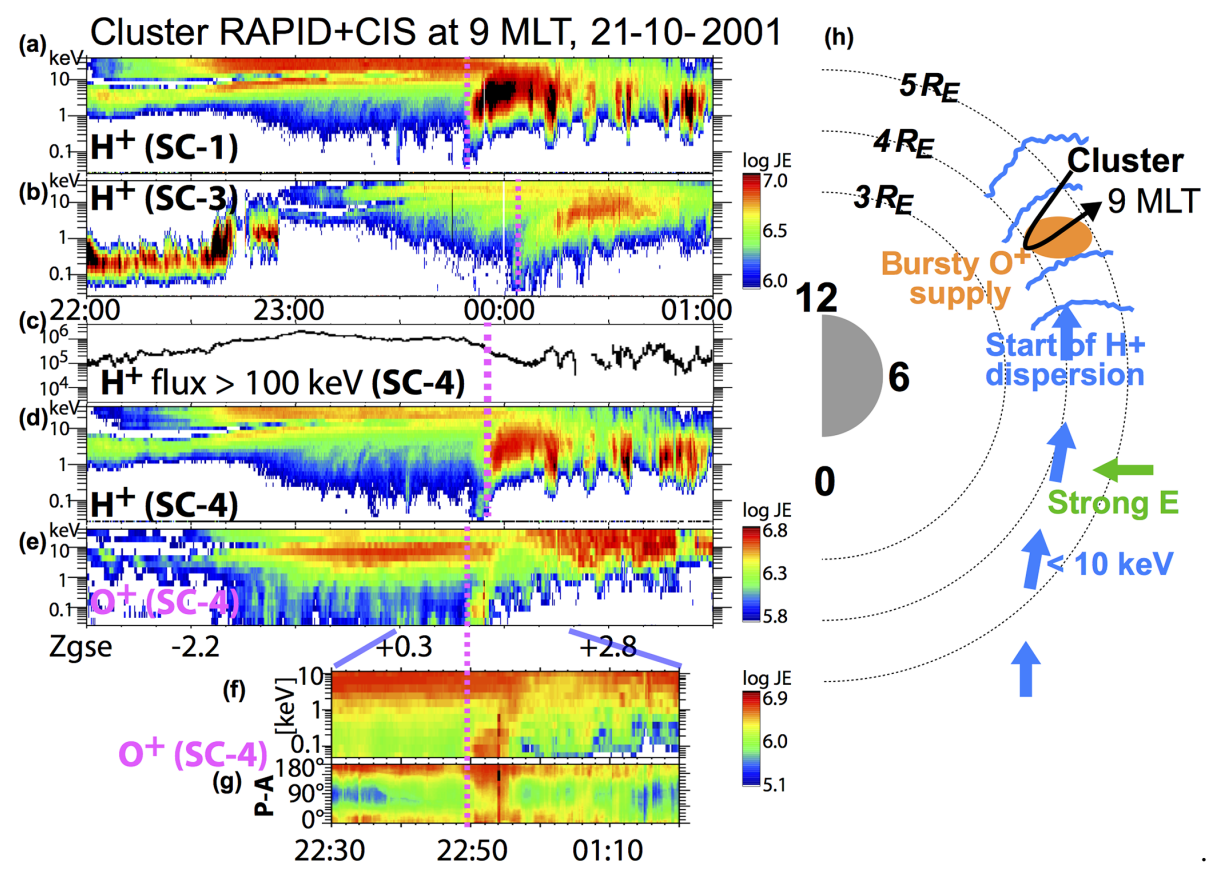

Figure 10. Summary of the Cluster observation and its interpretation of the sudden appearance of hot ions starting at around 21:50 UT on 21 October 2001 (Yamauchi et al., 2006a). Left: energy-time spectrograms of differential energy fluxes $\left(\mathrm{keV} \mathrm{cm}^{-2} \mathrm{~s}^{-1} \mathrm{sr}^{-1} \mathrm{keV}^{-1}\right)$ for protons from (a) spacecraft (SC)-1, (b) SC-3, and (d) SC-4 and (e) for heavy ions $\left(\mathrm{O}^{+}\right.$) from SC-4. For SC-4, (d) energetic proton flux is also plotted. The bottom panels show (f) a zoom-up of (e) and (g) energy-pitch angle spectrograms of the same data.

geosynchronous orbit, particularly in the nightside (Quinn and McIlwain, 1979; Hultqvist, 2002). In fact, ions at < $100 \mathrm{eV}$ with nearly field-aligned pitch angles are commonly found in the equatorial inner magnetosphere (Horwitz and Chappell, 1979; Yamauchi et al., 2013). They are normally without significant $\mathrm{O}^{+}$. In this sense, this is similar to the cold supersonic flow or cold filling and can be ignored in amount compared to plasmaspheric cold ions.

These ions are not necessarily inside the loss cone because energization to accelerate to suprathermal and hot energy involves perpendicular heating above the mirror point. Figure 9 shows one such example at 05:15-05:35 UT. The very weak dispersion ( $1 \mathrm{~min}$ from 30 to $200 \mathrm{eV}$ ) indicates a short elapsed time $(<15 \mathrm{~min})$, although it is still longer than the travel time from the ionosphere $(<5 \mathrm{~min})$ for $\mathrm{H}^{+}$outside the loss cone. This means that the source must be around 15 MLT and $63^{\circ} \mathrm{Inv}$, which is lower in latitude than where the beamlike outflow $>1 \mathrm{keV}$ is often observed (Lundin et al., 1995), but still within the region of outflow (Peterson et al., 2008).

On the other hand, direct $\mathrm{O}^{+}$outflow into the inner magnetosphere with finite pitch angles does exist. For example, Fig. 10 shows the appearance of low-energy $\mathrm{O}^{+}$at $<300 \mathrm{eV}$ in SC-4 at 23:50-23:55 UT with a peak at a $180^{\circ}$ pitch angle. $\mathrm{SC}-1$ also detected the same $\mathrm{O}^{+}$signature at 23:4423:51 UT at nearly the same latitude ( $L$ value). These $\mathrm{O}^{+}$signatures are without obvious energy-time dispersion (no timeof-flight effect) and are thus limited to a small source region, as illustrated in Fig. 10h. Considering the field-aligned ve- locity of low-energy $\mathrm{O}^{+}\left(20-40 \mathrm{~km} \mathrm{~s}^{-1}\right.$ for $\left.50-200 \mathrm{eV} \mathrm{O}^{+}\right)$ and the lack of mirrored ions outside the loss cone, these $\mathrm{O}^{+}$ must have left the northern ionosphere at 8-9 MLT about 1030 min continuously before the detection, with most likely no outflow before. This timing agrees with the substorm onset at around 23:10 UT and with the elapsed time of eastward-drifting ions that was calculated in Sect. 4.3. The late-morning to prenoon auroral and sub-auroral (closed geomagnetic field) region is known for strong ion outflow with a high $\mathrm{O}^{+} / \mathrm{H}^{+}$ratio and significant enhancement with substorm activity (Øieroset et al., 2000; Peterson et al., 2008). This event shows how quickly outflow starts after the substorm onset with $\mathrm{O}^{+}$dominance over $\mathrm{H}^{+}$.

A similar field-aligned burst is also seen in Fig. 11 at 06:48:30 UT, first coming from the Southern Hemisphere for $<100 \mathrm{eV}$ ions. The energy extends soon to nearly $1 \mathrm{keV}$ with a bouncing (nearly field-aligned bi-directional) signature. Unlike the $\boldsymbol{E} \times \boldsymbol{B}$ drift 5 min before, these ions contain $\mathrm{O}^{+}$(not shown here), indicating that they are directly coming from the ionosphere rather than being heated locally. The ionospheric conjugate point along the geomagnetic field corresponds to where the transpolar arc and the auroral bulge meet according to the IMAGE FUV data (Fig. 11d). Figure 11 also shows a sudden change in pitch angles for $\mathrm{keV}$ ions at around 06:44 UT, without any signature in the sub$\mathrm{keV}$ energy range. The timing and location correspond to the westward-travelling auroral bulge, and $\mathrm{keV} \mathrm{O}^{+}$flux was also enhanced, although it is less clear than the $\mathrm{H}^{+}$signature (Ya- 


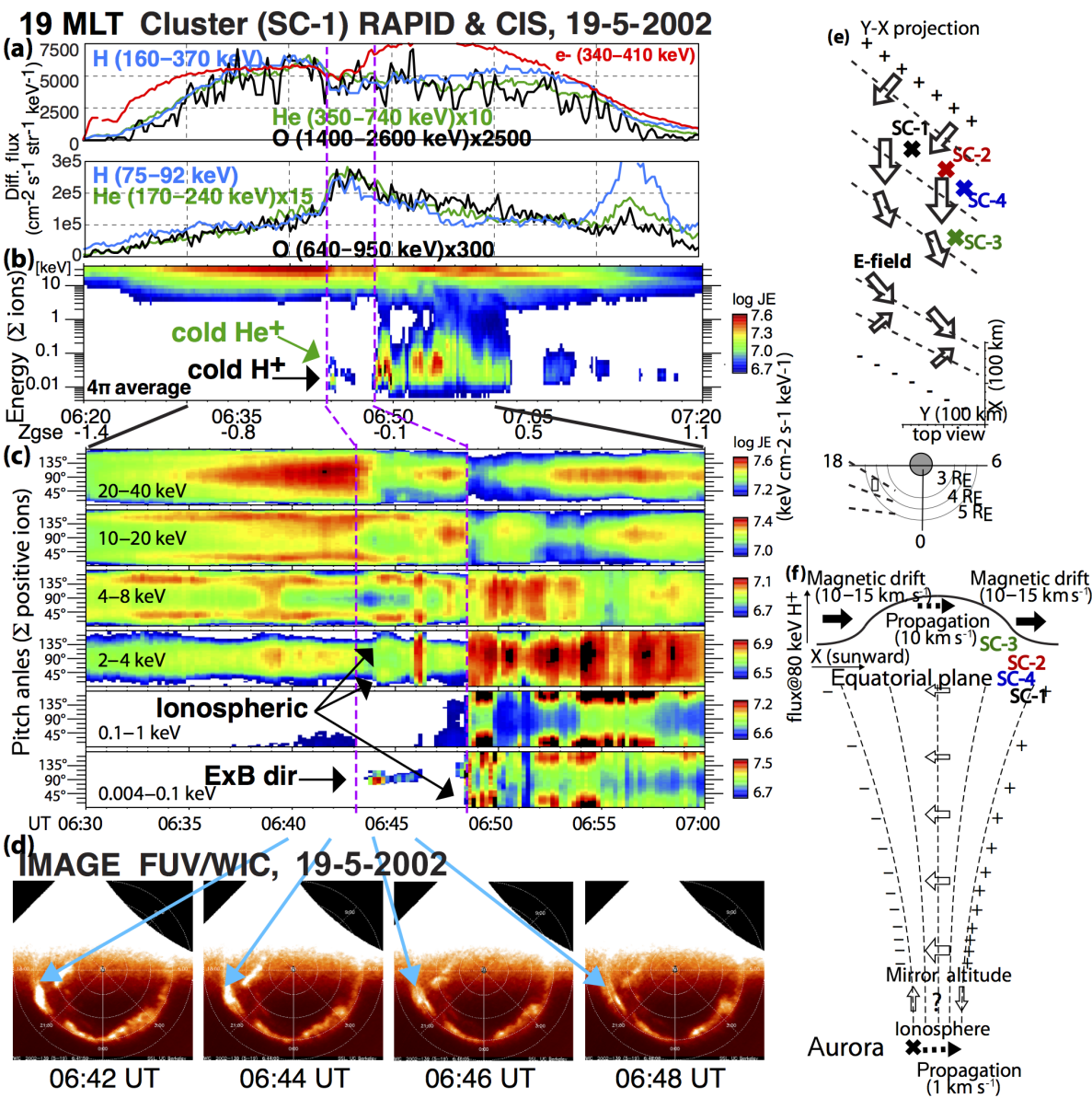

Figure 11. Summary of (a) Cluster energetic ion flux, (b) hot ion energy-time spectrograms and (c) energy-pitch angle spectrograms of differential energy fluxes $\left(\mathrm{keV} \mathrm{cm}^{-2} \mathrm{~s}^{-1} \mathrm{sr}^{-1} \mathrm{keV}^{-1}\right.$ ), (d) IMAGE observations, and (e) interpretation of ion behaviors at around 06:43 UT on 19 May 2002 (Yamauchi et al., 2009b). These ions at the equator, that is, conjugate with westward auroral bulge, are interpreted as a sunward propagation of the high-amplitude DC electric field accompanied by polarization.

mauchi et al., 2009b). The energy and location indicate that these outflowing ions are accelerated by the parallel electric potential drop over the auroral bulge.

Once ions coming directly from the ionosphere start to drift, it is difficult to distinguish them from the magnetotailorigin low-energy ions just from the energy spectrum. However, they normally have a different composition (Fig. 10) or pitch angle distributions (Fig. 9), as described above.

The mixing occurs even during quiet times and on a large scale, as shown in Fig. 12 (Giang et al., 2009). Wedge-like dispersed sub-keV $\mathrm{H}^{+}$with low pitch angles during 00:5501:18 UT is followed by the wedge-like dispersed sub-keV $\mathrm{O}^{+}$with high pitch angles without $\mathrm{H}^{+}$after $01: 18 \mathrm{UT}$. Thus, $\mathrm{H}^{+}$and $\mathrm{O}^{+}$are anti-correlated with different pitch angles. Such anti-correlation is seen already from 00:20 UT. The dispersion and low energy indicate that these ions drifted eastward from the morning (or even from the midnight) sector, and the different pitch angles indicate that only $\mathrm{O}^{+}$experienced substantial adiabatic energization and hence longer drift distance than $\mathrm{H}^{+}$. Since both magnetic and $\boldsymbol{E} \times \boldsymbol{B}$ drifts are mass independent, this observation suggests that $\mathrm{H}^{+}$injection was closer to the Earth than $\mathrm{O}^{+}$injection and that such a newer injection of $\mathrm{H}^{+}$expelled the pre-existing $\mathrm{O}^{+}$. The low pitch angles for $\mathrm{H}^{+}$also suggest that the injection point is in the inner magnetosphere rather than in the tail plasma sheet. Such anti-correlation events are not often observed, and all the events are observed during a relatively quiet time with $\mathrm{AE}<100 \mathrm{nT}$ (Giang et al., 2009).

\subsection{Local energization of low-energy ions}

Local energization of ions, particularly at less than a few $\mathrm{keV}$, is important when considering the trajectory and final destination of inner magnetospheric ions, because they are substantially altered after even a small amount of non-adiabatic energization, e.g., by the electric field (Ebihara and Ejiri, 2003). In addition to the equatorial perpendicular heating of cold ions (Fig. 6), local energization of hot ions is sometimes observed, associated with substorms and interplanetary coronal mass ejections (ICME). 


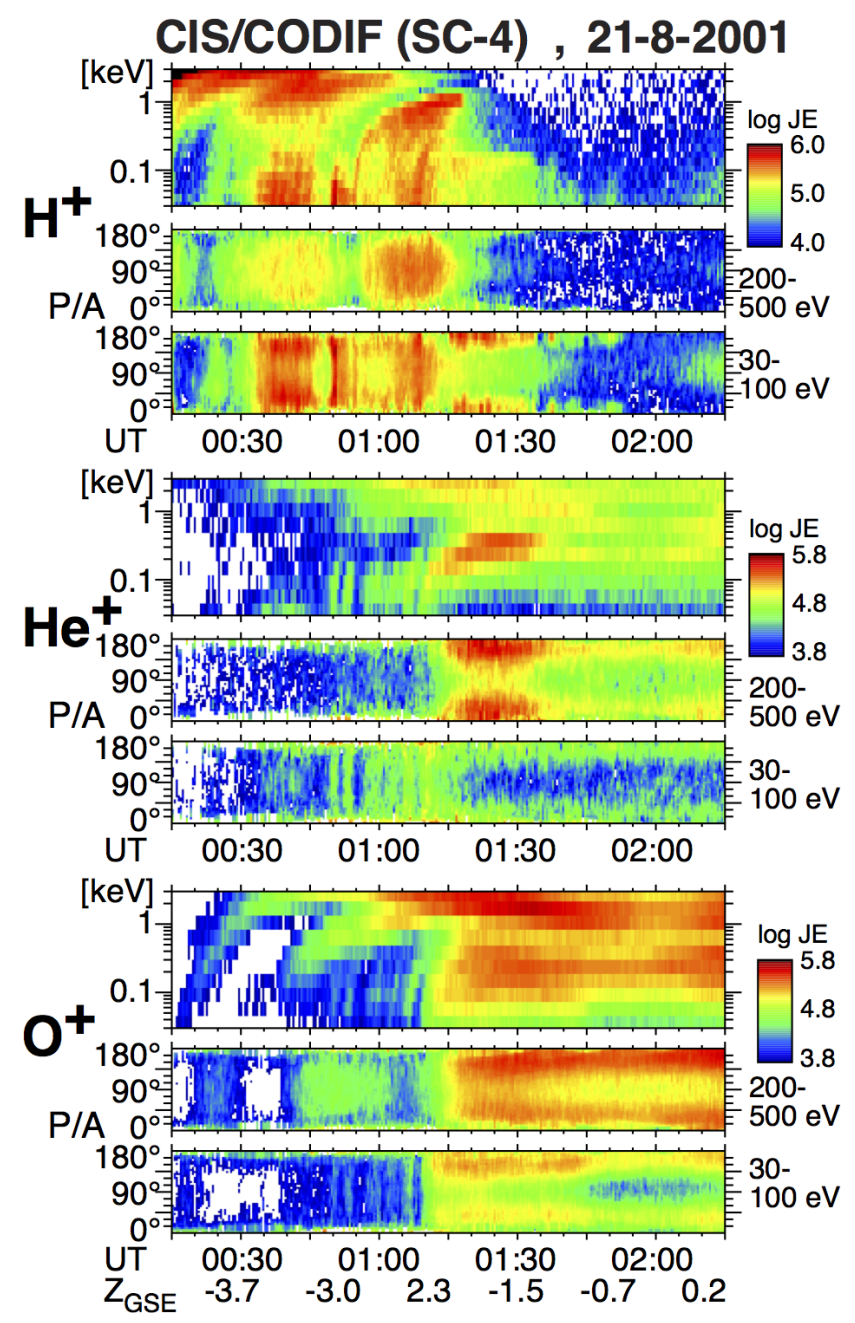

Figure 12. Cluster hot ion energy-time and energypitch angle spectrograms of differential energy fluxes $\left(\mathrm{keV} \mathrm{cm}^{-2} \mathrm{~s}^{-1} \mathrm{sr}^{-1} \mathrm{keV}^{-1}\right)$ from SC-4 on 21 August 2001 (Giang et al., 2009; Yamauchi et al., 2014a).

For example, a high-amplitude electric field propagating in the inner magnetosphere energizes particles effectively for both sunward propagation (Yamauchi et al., 2009b) and antisunward propagation (Araki et al., 1997), although they are barely observed. Figure 13 shows an example of ion energization by the anti-sunward propagation of shock in the inner magnetosphere when ICME with $2000 \mathrm{~km} \mathrm{~s}^{-1}$ velocity arrived at the Earth at the beginning of the Halloween storm event on 29 October 2003 (Yamauchi et al., 2006b). The propagation velocity inside the inner magnetosphere was as fast as the ICME velocity without delay and much faster than the propagation route through the ionosphere. Fast antisunward propagation of a shock is also reported in Zong et al. (2009), after which ultra-low-frequency (ULF) waves are generated in its trail. For the Halloween event, spacecraft in the midnight sector near the equatorial plane detected a dipolarization of the geomagnetic field starting only $20 \mathrm{~s}$ after the

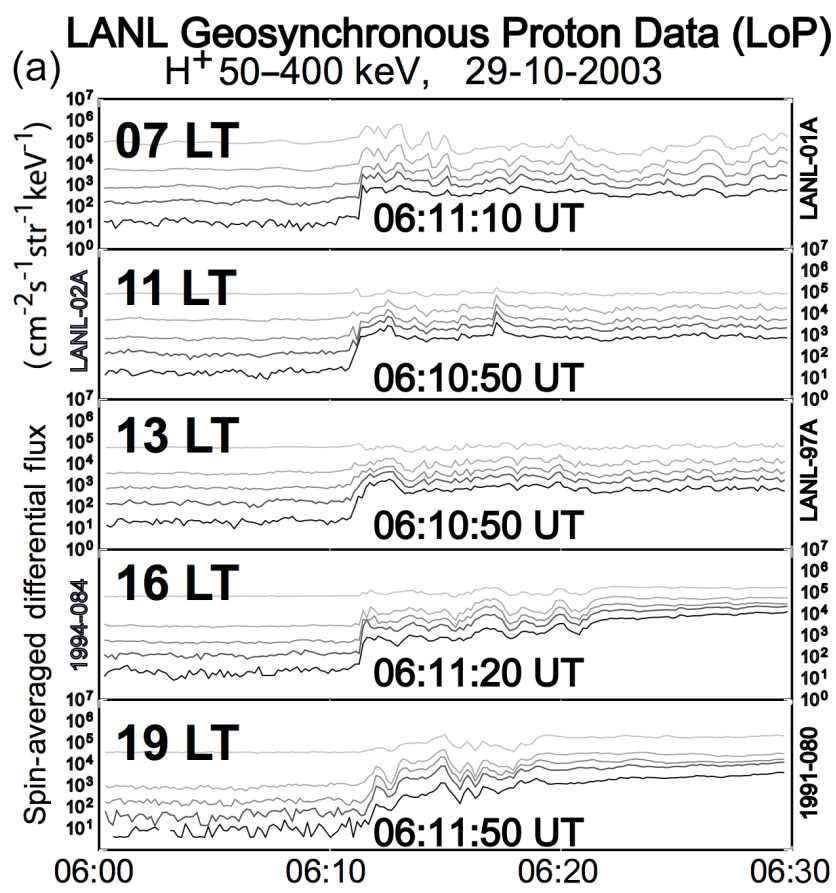

(b)

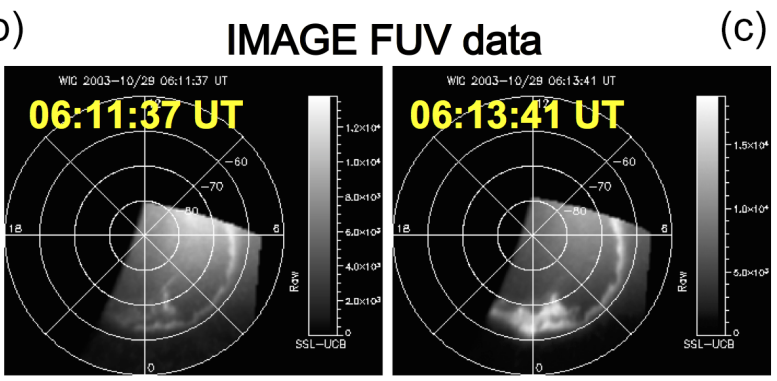

Figure 13. (a) Energetic proton flux $(50-400 \mathrm{keV})$ observed by the LANL geosynchronous satellites (LANL-01A at 07:00 LT, LANL02A at 11:00 LT, LANL-97A at 13:00 LT, 1994-084 at 16:00 LT, and 1991-080 at 19:00 LT) during the initial phase of the 29 October 2003 storm (06:00-06:30 UT). (b, c) IMAGE FUV data that show quick expansion of an auroral substorm at around 06:12 UT, which is confirmed by ground geomagnetic field data (Yamauchi et al., 2006b).

arrival of this shock at midnight, indicating that this triggered the dipolarization. Note that this is a rather unique event, and this onset mechanism may not be generalized.

Figure 11 shows the opposite example, i.e., sunward propagation of a large-amplitude polarization electric field in the equatorial inner magnetosphere after the substorm onset on 19 May 2002 (Yamauchi et al., 2009b). At about 06:43 UT, Cluster at around $L=4$ detected plasmaspheric cold $\mathrm{H}^{+}$and $\mathrm{He}^{+}$drifting duskward (perpendicular to the magnetic field) with high velocity up to $50-60 \mathrm{~km} \mathrm{~s}^{-1}$. Electric field measurements show an anti-sunward DC field up to $10 \mathrm{~m} \mathrm{~V}^{-1}$, in agreement with the $\boldsymbol{E} \times \boldsymbol{B}$ drift velocity for the observed geomagnetic field. The relative timing between four Cluster spacecraft indicates that this finite-amplitude $E$ field propa- 
gated sunward with a velocity of $5-10 \mathrm{~km} \mathrm{~s}^{-1}$, and hence the electric field is the polarization field with positive charges leading on the front side as illustrated in Fig. 11e and f. In the ionosphere, this electric field is mapped to a substorm auroral bulge at 19 MLT that has exactly the same sunward propagation velocity as this equatorial polarization electric field.

One unique feature is that the ring current ions at energy range $70-1000 \mathrm{keV}$ showed a mass-dependent flux enhancement together with a mass-dependent decrease in ions at energies above and below this range. The energy ratios of the enhanced $\mathrm{O}^{+}, \mathrm{He}^{+}$, and $\mathrm{H}^{+}$are about $16: 4: 1.5$; i.e., all species have nearly the same gyration speed of about $3000 \mathrm{~km} \mathrm{~s}^{-1}$. The mass-dependent decrease in flux at higher energy also has a similar gyration velocity for all species (about $5000 \mathrm{~km} \mathrm{~s}^{-1}$ ), whereas the decrease in flux at lower energy (Fig. 11c) was seen only in heavy ions (but not $\mathrm{H}^{+}$, which is below the lower-energy threshold of the ring current) at high pitch angles. Since both the magnetic and $\boldsymbol{E} \times \boldsymbol{B}$ drifts are mass independent, the energy enhancement is less likely to be caused by drifting of new injections from the nightside. Therefore, the propagating polarization structure with large amplitude most likely caused the mass-dependent flux enhancement of ions. One possibility is that ions with gyrating velocity higher and lower than $3000 \mathrm{~km} \mathrm{~s}^{-1}$ are somewhat decelerated/accelerated by this structure, but the mechanism is unknown.

ULF waves like Pc5 pulsation of $10^{-2} \mathrm{~Hz}$ that are common after large substorms also energize ions and electrons by the associated electric field. Waite et al. (1986) found a case when $\mathrm{He}^{+}$was modulated without $\mathrm{H}^{+}$modulation for cold ions of $<10 \mathrm{eV}$. Yamauchi et al. (1996) found that the drifting hot trapped ions are almost always modulated in energy by tens to hundreds of $\mathrm{eV}$, forming a bundled structure when the Pc5 in the azimuthal geomagnetic field is present. Such energy modulation is mainly found at $L \leq 4\left(\leq 60^{\circ}\right.$ Inv), which Cluster does not cover. In addition, a case of strong conic-like energization near the loss cone boundary of these trapped ions is found. The mechanism of the conic-like energization is still unexplained.

\subsection{Composition}

Since different sources and energization mechanisms have different $\mathrm{H}^{+} / \mathrm{He}^{2+} / \mathrm{He}^{+} / \mathrm{O}^{+} / \mathrm{N}^{+}$ratios at given energies, the composition of inner magnetospheric ions is quite different at different locations (Welling et al., 2011). Furthermore, even the same source such as the tail plasma sheet may cause the local time dependence of composition, because, for example, bursty $\mathrm{O}^{+}$return flow is not aligned to bursty $\mathrm{H}^{+}$ return flow (Nilsson et al., 2016). Relevant statistics together with the mass-dependent energization in the inner magnetosphere as listed above remain unsolved issues. On the other hand, general abundance of heavy ions (both the $\mathrm{O}^{+} / \mathrm{H}^{+}$ ratio and the $\mathrm{N}^{+} / \mathrm{O}^{+}$ratio) is known to increase with geo- magnetic activity (Hamilton et al., 1988; Daglis et al., 1999; Maggiolo and Kistler, 2014), as is expected from the higher outflow rate from the ionosphere for higher geomagnetic activities as described in Sect. 2.3. Geomagnetic dependence of the escaping $\mathrm{O}^{+}$to space is also very strong, as is described in Sect. 3.3 (Schillings et al., 2019).

\subsection{Loss process}

In the drift model (Sect. 4.1), all drift components except the $\boldsymbol{E} \times \boldsymbol{B}$ drift by the external electric field keep ions trapped in the inner magnetosphere, like the inner radiation belt where the effect of the external electric field is negligible. However, the $\boldsymbol{E} \times \boldsymbol{B}$ drift by the external electric field drives inner magnetospheric ions in one direction rather than rounding the Earth, making them reach the magnetopause. Once the ions reach the magnetopause, these drifting ions can leak outside the magnetopause and start moving in the same direction as the anti-sunward (e.g., magnetosheath) flow through the ion pickup process.

This is called magnetopause shadowing and is most effective for ions with high pitch angles $\left(\alpha=90^{\circ}\right.$ in Eq. 1) for the same energy (Blanc et al., 1999), making ion pitch angle distribution at the equator oblique ("butterfly" distribution). Magnetopause shadowing does not require local magnetopause reconnection (Sibeck et al., 1987, 1999; Sauvaud et al., 2001; Marcucci et al., 2004), while it is most effective during strong sunward convection sustained by nightside activities or during magnetopause erosion, both of which take place during increasing solar wind dynamic pressure and southward turning of the IMF. Therefore, this process very often coexists with the local magnetopause reconnection (Toledo-Redondo et al., 2016; Fuselier et al., 2017).

Magnetopause shadowing is well known for detached cold plasmaspheric plumes as described in Sect. 4.2. In addition, hot sub-keV ions in the dayside inner magnetosphere experience the same evacuation mechanism from the inner magnetosphere because the westward magnetic drift cancels the eastward cororation to stay in the same local time sector for a sufficiently long time to reach the magnetopause by the remaining sunward convection component. This means that, if no ions are supplied from the nightside plasma sheet, sub$\mathrm{keV}$ (and even $\mathrm{keV}$ ) ions will be evacuated through magnetopause shadowing. Such ion evacuations are observed at the start of the magnetic storm before the first ions inject (Hultqvist et al., 1981; Yamauchi and Lundin, 2006). Even a substantial portion of tens of $\mathrm{keV}$ ions are most likely lost through magnetopause shadowing, because this explains the observed butterfly pitch angle distribution very well.

For high-energy ions, magnetopause shadowing becomes less important compared to the other loss mechanisms, such as charge exchange, Coulomb collisions with thermal plasma, and pitch angle scattering to the loss cone by waves (Blanc et al., 1999; Ebihara and Ejiri, 2003). The efficiency of these local processes of ion loss is well understood for en- 
ergy $>1 \mathrm{keV}$ (Fok et al., 1991; Ebihara and Ejiri, 2003), with a much shorter lifetime for the ordinary ring current (around $10 \mathrm{keV}$ for $\mathrm{H}^{+}$and $>100 \mathrm{keV}$ for $\mathrm{O}^{+}$) than the sub-keV ions. Here, Coulomb collision mainly decreases the ion energy rather than scattering ions into the loss cone and hence contributes less to the ion loss from the inner magnetosphere than the other loss mechanisms (Fok et al., 1991). Among these local loss processes, scattering into the loss cone is dominant for radiation belt particles (Blanc et al., 1999; Ebihara and Ejiri, 2003).

On the other hand, the local loss process becomes less efficient for lower-energy ions (Ebihara and Ejiri, 2003), and magnetopause shadowing becomes the most effective loss mechanism for sub-keV ions, followed by charge exchange. In fact, the superposed statistics in terms of the delay time from the substorm onset (injection of the sub-keV ions) showed a sudden decrease in the observation rate of "substorm fossil" sub-keV ions when these ions reach the noon sector (Yamauchi and Lundin, 2006), where magnetopause shadowing is the most efficient. Also, ion drift simulations with charge-exchange loss alone can reproduce the energylatitude dispersion of sub-keV ions in the dayside (Ebihara et al., 2001, 2004; Yamauchi et al., 2009a, 2014b).

Among these loss mechanisms, magnetopause shadowing contributes the complete loss of ions from the magnetosphere, whereas scattering into the loss cone brings ions back to the ionosphere. Charge exchange is in between when only trapped ions bouncing in the magnetic bottle are considered, because the energetic neutral atoms (ENA) produced by this mechanism may point both toward the Earth and toward space depending on timing with respect to the mirror point (before or after). Here, most of the ions even with low pitch angles that are observed by Cluster are bouncing because the loss cone at the equator is on the order of only $1^{\circ}$. Since the neutral atmospheric density is maximum near the mirror point where the ions are gyrating in nearly horizontal directions, roughly half the ions move toward the Earth and half toward space. Altogether, approximately half the ENA is lost and half returns to the atmosphere.

\section{Consequences of a large amount of direct $\mathrm{O}^{+}$escape}

\subsection{Summary of the $\mathrm{O}^{+}$budget}

Figure 4 summarizes the major ion escape routes that are described in this paper. The first route (marked as d in Fig. 4) is the direct mixing with the solar wind into the magnetosheath and plasma mantle. All hot $\mathrm{O}^{+}$in the magnetosheath and a large part of $\mathrm{O}^{+}$in the plasma mantle contribute to the net escape. Since hot $\mathrm{O}^{+}$observed in this region is normally energized to the low-energy threshold of Cluster/CIS $(>28 \mathrm{eV})$, one may ignore contributions from $\mathrm{O}^{+}$with less energies when discussing the total flux. Slapak et al. $(2013,2017 \mathrm{a})$ and Schillings et al. (2019) have estimated the $\mathrm{O}^{+}$loss rate after considering the destinations of the plasma mantle flow.

The second route (marked as c in Fig. 4) is through the tail lobe and the tail plasma sheet, from where some ions move further anti-sunward and some return earthward. For hot $\mathrm{O}^{+}$, Slapak et al. (2017b) and Slapak and Nilsson (2018) estimated the anti-sunward and sunward fluxes, respectively, in both the plasma sheet and tail lobe. For cold supersonic ions, Engwall et al. (2009) estimated the total amount of ions flowing through the lobe into the tail plasma sheet as $8 \times 10^{25} \mathrm{~s}^{-1}$. Considering the low $\mathrm{O}^{+} / \mathrm{H}^{+}$ratio $\left(<10^{-2}\right.$, Sect. 3.2), this means that the total $\mathrm{O}^{+}$flux in the lobe is less than $0.1 \times 10^{25} \mathrm{~s}^{-1}$ and can be ignored compared to the first route when considering $\mathrm{O}^{+}$.

The returning flow from the tail does not necessarily return to the ionosphere. Rather, a large portion (more than half for the sub-keV ions and nearly half for the ring current ions) escapes through magnetopause shadowing and charge exchange. The same loss mechanisms (to space) apply to ions coming from the nightside auroral zone. Although a substantial part of the outflowing $\mathrm{O}^{+}$does not precipitate into the other hemisphere (see Sect. 3.3) and can follow a similar fate to the ions in the plasma sheet, this contribution to the total budget is very minor.

The third route (marked as b1 in Fig. 4) is direct supply to the inner magnetosphere such as in Fig. 10. While there are some statistics using geosynchronous satellites, so far no statistics exist for $\mathrm{O}^{+}$flux. On the other hand, the flux, particularly for $\mathrm{O}^{+}$, is very small and can safely be ignored when discussing the total amount of escape.

The last route is through refilling of the plasmasphere (marked as a in Fig. 4). Although dominated by $\mathrm{H}^{+}(90 \%)$ and $\mathrm{He}^{+}(10 \%)$ with only $1 \%-5 \%$ for $\mathrm{O}^{+}$(Sandel, 2011), the average $\mathrm{O}^{+}$escape rate can be as much as $2 \times 10^{25} \mathrm{~s}^{-1}$, as described in Sect. 2.1. Because of their low energies with very small field-aligned velocities, the majority of them are expected to escape by magnetopause shadowing or tailward detachment.

Table 1 summarizes the $\mathrm{O}^{+}$escape rate from the present Earth through these major escape routes. The direct escape from the magnetosheath and plasma mantle, after nonthermal heating in the dayside polar region, accounts for the majority of $\mathrm{O}^{+}$escape from the present Earth. The total escaping flux through this route drastically increases with increasing geomagnetic activity and the solar wind energy input, as summarized in Table 1 and Fig. 3 (Slapak et al., 2017a; Schillings et al., 2017, 2019). Since Kp is defined as a nearly logarithmic scale of geomagnetic disturbances in $\mathrm{nT}$, the exponential dependence given in Table 1 means nearly a power law dependence on the geomagnetic disturbance. The power law dependence is also seen between the solar wind energy input and the escape flux (Schillings et al., 2019).

Such a large amount of $\mathrm{O}^{+}$escape results in many consequences. In the past, the importance of $\mathrm{O}^{+}$in magnetospheric dynamics, for example for the substorm onset, has long been 
discussed and studied in both observations and simulations (Kistler et al., 2005; Kronberg et al., 2014). Modeling of such a mass-loading effect in the magnetosphere has been improved in recent years by expanding the destination to the low-latitude dayside magnetopause (Fuselier et al., 2017) or by improved simulation of $\mathrm{O}^{+}$outflow flux, e.g., by treating cusp outflow separately from the other outflow in simulation (Glocer et al., 2018). Even the importance of the feedback to the auroral ionosphere in modeling has long been pointed out (e.g., Moore et al., 2014). However, the importance of $\mathrm{O}^{+}$in the cusp and plasma mantle, its feedback to the ionosphere, and the effect on a geological timescale have not been well studied because these have been underestimated until recently. These topics will be briefly explained below.

\subsection{Importance of $\mathrm{O}^{+}$escape for solar wind interaction}

The active role of the mixing of $\mathrm{O}^{+}$into the solar wind in the flow dynamic in the magnetosheath and plasma mantle has long been overlooked, although its importance has previously been suggested (Yamauchi and Lundin, 1997; Winglee et al., 2002). This is partly because the $\mathrm{O}^{+}$density had been considered small compared to the incoming solar wind density before Cluster made quantitative statistics of the $\mathrm{O}^{+}$abundance in the incoming solar wind in the magnetosheath, the cusp, and the plasma mantle.

The observed $\mathrm{O}^{+}$abundance in the plasma mantle is about $1 \%$ and hence nearly $20 \%$ of the mass density due to the 16 times heavier mass of $\mathrm{O}^{+}$than $\mathrm{H}^{+}$. The $20 \%$ mass loading means a $10 \%$ decrease in the inflowing solar wind velocity $\left(u_{\text {inflow }}\right)$ and a $10 \%$ decrease in the total kinetic energy $(K)$ of the solar wind and the mass-loading $\mathrm{O}^{+}$when the mass loading of $\mathrm{O}^{+}$is completed; i.e., the anti-sunward velocity of $\mathrm{O}^{+}$ catches up with that of the solar wind. Cluster observations showed a substantial deceleration of the solar wind together with an anti-sunward acceleration of $\mathrm{O}^{+}$in the plasma mantle, indicating that mass loading is substantial (Yamauchi and Slapak, 2018b).

Unlike comets and unmagnetized planets, the charges initially separated during the deceleration of the solar wind by the mass loading can flow along the geomagnetic field to the conducting ionosphere to cancel the charge, as illustrated in Fig. 14. Thus, the surplus kinetic energy can maintain the electric current circuit that closes in the ionosphere near the cusp, which is geomagnetically connected to the entire massloading region at high altitudes.

The principle is the same as the reconnection (Dungey, 1961), except that this process works only where $\mathrm{O}^{+}$can access the solar wind rather than the geomagnetic open-closed configuration, and hence this mechanism works only in a local region rather than globally. Thus, the current system by the mass loading is independent of the global current system and can explain the observed independency between the cusp region 1 field-aligned current and non-cusp dayside region 1 field-aligned current (Ohtani et al., 1995; Yamauchi and

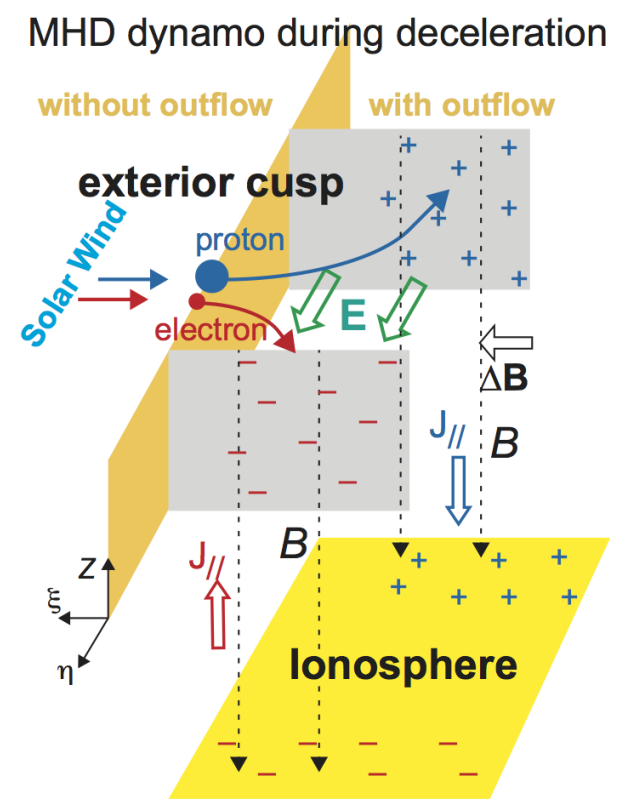

Figure 14. Illustration of the azimuthal charge separation when the solar wind inflow is decelerated by the start of mass loading with the outflowing ionospheric ions (Yamauchi and Slapak, 2018b). The boundary of the start of the outflowing region is shown as an orange plane. The positive (negative) charges are always deflected by the geomagnetic field $\boldsymbol{B}$ in the opposite direction to (along) the motional electric field $\boldsymbol{E}$, resulting in a dynamo current that causes a magnetic deviation $(\Delta \boldsymbol{B})$. Because of the connectivity to the ionosphere where the charges can move across the magnetic field, the accumulated charges form a current circuit through the field-aligned currents $\left(J_{\|}\right.$with blue and red arrows giving directions along $\boldsymbol{B}$ ) closing in the ionosphere.

Slapak, 2018a). The concept of such double openness, i.e., two-time definition of the open-closed boundary (by the solar wind access point to the magnetosphere, and by the access point of the outflowing ionospheric ions to the solar wind), is similar to the multiple-branch discontinuity model by Vasyliunas (1995) and the geopause concept by Moore and Delcourt (1995). The present model replaces these models' upward propagation of electrodynamic information of the ionosphere with the physical ion motions.

Yamauchi and Slapak (2018b) obtained an upper limit of the extraction rate of the total kinetic energy by the mass loading of escaping ions $(\Delta K)$ as

$\Delta K \sim-\frac{1}{4} F_{\text {load }}^{\prime} u_{\text {inflow }}^{2}$,

where $F_{\text {load }}^{\prime}$ is total mass flux of the escaping ions into the mixing region with the solar wind (the cusp, the plasma mantle, and the magnetosheath). Equation (4) does not include the solar wind density or the IMF in the first approximation. Instead, $\Delta K$ depends on the total escaping mass flux, which strongly depends on both $\mathrm{Kp}\left(\propto e^{0.45 \mathrm{Kp}}\right)$ and the solar wind dynamic pressure ( $\propto p_{\mathrm{SW}}^{1.5}$ according to Fig. 3) or velocity 
when the upstream solar wind velocity exceeds $500 \mathrm{~km} \mathrm{~s}^{-1}$ (Slapak et al., 2017a; Schillings et al., 2019).

Although the process is local, the energy conversion rate of $10 \%$ (cf. the same order of magnitude as the reconnection rate; Sonnerup, 1974) gives about $\Delta K \sim 0.3-1 \times$ $10^{10} \mathrm{~W}$, which is sufficient to explain the cusp current system (Potemra, 1994; Yamauchi and Slapak, 2018a). Furthermore, this current system forms a strong positive feedback between the escaping flux and the extracting energy, guaranteeing stronger solar wind dependence of the energy conversion than the global reconnection. This agrees with higher Kp dependence of dayside outflow compared to the nightside outflow and with the drastic solar wind dependence (particularly the dynamics pressure) of dayside outflow (Moore et al., 1999a). In this sense, the $\mathrm{O}^{+}$outflow is relevant even to space weather in addition to ionospheric physics (Yamauchi et al., 2018).

\section{$5.3 \mathrm{O}^{+}$escape on geological scale}

Before Cluster confirmed the large amount of $\mathrm{O}^{+}$escape through direct mixing with the solar wind, $\mathrm{O}^{+}$escape had been considered negligible in the evolution of the atmosphere and biosphere even on a geological scale of over 1 billion years $\left(\sim 3 \times 10^{16} \mathrm{~s}\right)$. If one uses a simple value of $10^{26} \mathrm{~s}^{-1}$ $\left(\sim 0.3 \mathrm{~kg} \mathrm{~s}^{-1}\right)$, the total amount of oxygen loss to space over 1 billion years is only $\sim 1 \times 10^{16} \mathrm{~kg}$ and is negligible compared to the present atmospheric mass $\left(1 \times 10^{18} \mathrm{~kg}\right.$ for oxygen and $4 \times 10^{18} \mathrm{~kg}$ for nitrogen).

However, the solar EUV flux, solar rotation, and solar wind in ancient times were most likely much higher and faster than in the present day due to much faster solar rotation compared to the present (Ribas et al., 2005; Wood, 2006; Airapetian and Usmanov, 2016). The fast rotation also means a strong solar dynamo magnetic field and IMF in ancient times. Therefore, we expect a high $\mathrm{Kp}$ as the average in ancient times. Due to the exponential dependence of the $\mathrm{O}^{+}$escape on $\mathrm{Kp}$ as summarized in Table 1, the ancient conditions suggest very high escape rates exceeding $10^{27} \mathrm{~s}^{-1}$. This gives already $>10^{17} \mathrm{~kg}$ or $10 \%$ of atmospheric oxygen content over 1 billion years. Considering that biological activities are sensitive to the $\mathrm{O} / \mathrm{N}$ ratio of the atmosphere (e.g., Loesche, 1969; Hill, 1976; Harrison, 2010), this can no longer be ignored. If the escape rate reaches $10^{28} \mathrm{~s}^{-1}$, as is suggested by Krauss et al. (2012) and Slapak et al. (2017a), only 100 million years is enough to affect the bioactivity.

Thus, although oxygen can be supplied from the ocean, the atmospheric escape to space could have played some role in the evolution of the biosphere. However, before making any quantitative model estimates, we must also consider many other factors, such as the neutral escape due to the higher UV flux and weaker terrestrial dynamo (smaller magnetosphere) in ancient times, as illustrated in Fig. 15 (Yamauchi and Wahlund, 2007). High UV increases the thermospheric temperature and hence expands the thermosphere and the ex-

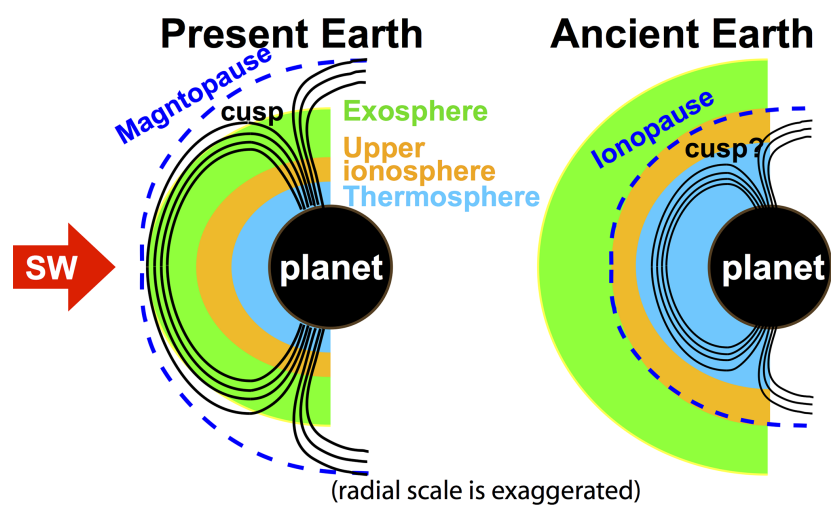

Figure 15. Illustration of differences in the magnetosphere, exosphere, and ionosphere between the present and ancient Earth (cf. Yamauchi and Wahlund, 2007).

Table 2. Escape energy from the Earth at different heights.

\begin{tabular}{lrrr}
\hline height & $500 \mathrm{~km}$ & $2000 \mathrm{~km}$ & $10000 \mathrm{~km}$ \\
\hline velocity & $10.8 \mathrm{~km} \mathrm{~s}^{-1}$ & $9.8 \mathrm{~km} \mathrm{~s}^{-1}$ & $7.0 \mathrm{~km} \mathrm{~s}^{-1}$ \\
$\mathrm{O}$ & $9.7 \mathrm{eV}$ & $8.0 \mathrm{eV}$ & $4.1 \mathrm{eV}^{\mathrm{a}}$ \\
$\mathrm{N}$ & $8.5 \mathrm{eV}$ & $7.0 \mathrm{eV}$ & $3.6 \mathrm{eV}^{\mathrm{b}}$ \\
\hline
\end{tabular}

${ }^{\mathrm{a}} \mathrm{O}_{2}^{+}+e^{-} \rightarrow 2 \mathrm{O}+1-7 \mathrm{eV} .{ }^{\mathrm{b}} \mathrm{N}_{2}^{+}+e^{-} \rightarrow 2 \mathrm{~N}+3-6 \mathrm{eV}$.

osphere, although cooling by a larger amount of $\mathrm{CO}_{2}$ in the ancient atmosphere will somewhat ease this change (Tian et al., 2008). The increased exobase altitude reduces the escape energy as summarized in Table 2 and makes thermal escape after photochemical heating much more effective.

Because of the weaker terrestrial dynamo and stronger solar wind in ancient times, the sub-solar magnetopause where the solar wind dynamic pressure and the magnetic pressure of the geomagnetic field balance is moved toward the Earth (Yamauchi and Wahlund, 2007). As a result, neutrals of the expanded exosphere are exposed to the solar wind, and they start contributing to the escape, as on Mars (Dubinin et al., 2006). The expanded thermosphere and exobase are normally accompanied by an expanded ionosphere, making the Earth even more of a non-magnetized planet in terms of atmospheric escape. Altogether, the neutral escape might become important, although we do not have enough observational knowledge of many of them for quantitative modeling, as summarized in Table 3. Nevertheless, the escape rate should be more than what is obtained from the ion escape only, and less than 100 million years might be enough for atmospheric escape to affect the bioactivity in the past on a geological scale.

Our observational knowledge is not sufficient for even the present-day neutral distribution in the exosphere and upper thermosphere. The empirical average such as the MSIS model is not sufficient to model the upper thermosphere and exosphere when modeling the escape (e.g., Meier et al., 
Table 3. Major mechanisms of atmospheric loss to space.

\begin{tabular}{llll}
\hline mechanism & present Earth & ancient Earth & knowledge needed \\
\hline Jeans escape & (negligible) & yes? & present exosphere \\
Hydrodynamic blow-off & (negligible) & yes? & present exosphere \\
Momentum exchange & (negligible) & yes? & present exosphere \\
Photochemical energization & (negligible) & yes & present exobase \\
Charge exchange & yes & $?$ & ring current \\
Atmospheric sputtering & (negligible) & yes? & past cusp \\
Ion pickup & (negligible) & yes & \\
Ions accelerated by EM field reach SW & yes & yes & \\
Large-scale momentum transfer and instabilities by the solar wind interactions & yes & yes? & past magnetosphere \\
Magnetopause shadowing (ions) & yes & yes? & past ring current \\
Plasmaspheric wind and plumes & yes & yes? & past plasmasphere \\
\hline
\end{tabular}

2015; Lakhina and Tsurutani, 2017). For example, the local extent of the exosphere, which is one of the most basic parameters, is sensitive to solar UV and geomagnetic activities (Zoennchen et al., 2015, 2017), but the data are not sufficient to include them in the empirical model. Also, the extent of the Martian exosphere that is estimated from the production of newly ionized exospheric hydrogen changes by an order of magnitude (seen as pickup ion flux), with only a factor of 2 difference in the solar UV (Yamauchi et al., 2015).

Unfortunately, in situ studies at the Earth were not possible due to the lack of proper neutral instruments at the altitude range 500-5000 km. However, we can gather relevant information from the present Earth with proper instrumentation by exploring less-studied regions, as indicated in the last column of Table 3. To understand neutral dynamics and neutral escape from altitudes above the exobase, we need a dedicated space mission to study both ion escape and neutral escape from the present Earth (Dandouras et al., 2016, 2018).

\section{Discussion}

This paper reviews the transport and loss of terrestrial ions and the relevant behaviors of hot heavy ions in the inner magnetosphere where outflowing ions from different routes mix together, with the main stress on Cluster's findings that are overlooked in other recent reviews. Cluster is the first mission that covers all important regions for ion escape, including the polar magnetospheric boundary and plasmasphere with proper instruments, allowing quantitative estimates as summarized in Table 1. While the most important routes and dynamics that are relevant to $\mathrm{O}^{+}$escape are covered, many other ion phenomena are not included. A full description would require an entire book.

The major loss mechanisms for the inner magnetospheric ions, if the changes of the path through non-adiabatic energization are ignored, are magnetopause shadowing, charge exchange, and scattering to the loss cone. Because of the energy dependence of these mechanisms, the return rate of $\mathrm{O}^{+}$ to the ionosphere is higher for higher-energy ions, but its upper limit is about $50 \%$. In other words, the energization in the inner magnetosphere increases the return rate, but by no more than a factor of 2 . This is in contrast to the energization above the ionosphere, which enhances the escape rate. Since the $\mathrm{O}^{+}$return rate entering the inner magnetosphere is about $50 \%$ or less, while all the other outflowing ions escape to space, the most important factor that determines the ion escape is the total outflow flux above the ionosphere. In this sense, the outflow value at much lower altitude than Cluster is important, but only if the ion instrument can cover the entire energy range. Unfortunately, this has not been achieved, and the past observations show a significant increase in the escape flux with altitude (Lennartsson et al., 2004).

The consequences of $\mathrm{O}^{+}$outflow and dynamics extend broadly, including ionospheric physics, solar wind interaction with the magnetosphere, space weather, and astrobiology, in addition to the effect on magnetospheric activities such as substorms (e.g., Kistler et al., 2005; Kronberg et al., 2014). For example, the outflow flux is sufficient to activate the mass-loading type energy conversion from the solar wind to the electric current system that closes in the cusp ionosphere, which is independent of the current system driven by the global solar wind-magnetosphere interaction (Yamauchi and Slapak, 2018b). The total escape rate of $\mathrm{O}^{+}$to space might have even played some role in the evolution of the biosphere through the change in the atmospheric composition of more than a few percent (Slapak et al., 2017a; Dandouras et al., 2018). However, these new applications are not yet quantitatively confirmed by dedicated observations or modelings, with only preliminary models or indirect observations (Winglee et al., 2002; Yamauchi and Slapak, 2018b). Dedicated work and missions are needed to explore the questions raised by these observations. 


\section{Conclusions}

The ion outflow from the ionosphere can be classified into three categories when observing in the magnetosphere: (1) cold filling, (2) cold supersonic outflow, and (3) suprathermal and hot outflow. The outflowing suprathermal ions $(<50 \mathrm{eV})$ above the ionosphere are most likely to be observed as hot ions in the magnetosphere. Direct destinations of these outflows (Fig. 4) range from the plasmasphere (innermost) to direct entry into the solar wind in the polar region (outermost). From these destinations, ions start to either circulate in the magnetosphere or escape to space. Out of these three types of outflow, hot outflow alone causes a high escape rate to space for $\mathrm{O}^{+}$as summarized in Table 1, and hence non-thermal heating is the most contributing mechanism for ion escape (Table 3 ).

As a result of the secondary transport (circulation) and direct injection, the inner magnetosphere becomes a zoo of many different low-energy ions (direct supply from the ionosphere including bouncing ions, and drifting ions from the nightside plasma sheet) and different mechanisms of energization and transport. Some of these mechanisms are still poorly understood. In particular, Cluster observed many mass-dependent energizations and transports (e.g., Figs. 6, 7, 11a, and 12), although the observations were made below the geosynchronous distance where the mass-independent drift theory is well qualified.

The total observed flux of the terrestrial ion and its drastic dependency on the solar wind condition indicate that the ion outflow plays active roles in two subjects that have been overlooked in the past, in addition to its role in the magnetospheric dynamics. One is the mass-loading effect into the solar wind, which can explain the energy conversion to sustain the cusp current system quantitatively. This interaction promotes the second openness of the magnetosphere, where the open-closed boundaries are defined twice, by the solar wind access point to the magnetosphere and by the ionospheric ion access point to the solar wind. The other is its influence on the atmospheric evolution on a geological scale after taking into account the higher solar and solar wind activity in the past, although more complete observations and modeling are needed to answer this question. Such studies require a new dedicated mission on atmospheric escape.

Code and data availability. Cluster plotting software and data are available at the Cluster Science Archive through https://www. cosmos.esa.int/web/csa/access (last access: 11 December 2019; European Space Agency, 2013).

Competing interests. The author declares that there is no conflict of interest.
Acknowledgements. The author appreciates the EGU's offer of a special opportunity to give a lecture at the General Assembly 2019. The author thanks Rickard Lundin, Iannis Dandouras, Yusuke Ebihara, Hans Nilsson, and all past co-authors in preparing the manuscript and the EGU lecture. The author would like to dedicate this work to the memory of Bengt Hultqvist, the first director of the Swedish Institute of Space Physics, who passed away in February 2019.

Review statement. This paper was edited by Ioannis A. Daglis and reviewed by two anonymous referees.

\section{References}

Abe, T., Whalen, B. A., Yau, A. W., Horita, R. E., Watanabe, S., and Sagawa, E.: EXOS D (Akebono) suprathermal mass spectrometer observations of the polar wind, J. Geophys. Res., 98, 11191-11203, https://doi.org/10.1029/92JA01971, 1993.

Airapetian, V. S. and Usmanov, A.: Reconstructing the Solar Wind from Its Early History to Current Epoch, Astrophys. J. Lett., 817, L24, https://doi.org/10.3847/2041-8205/817/2/L24, 2016.

André, M.: Previously hidden low-energy ions: a better map of nearEarth space and the terrestrial mass balance, Phys. Scripta, 90, 128005, https://doi.org/10.1088/0031-8949/90/12/128005, 2015.

Araki, T., Fujitani, S., Emoto, M., Yumoto, K., Shiokawa, K., Ichinose, T., Luehr, H., and Orr, D.: Anomalous sudden commencement on March 24, 1991, J. Geophys. Res., 102, 14075-14086, https://doi.org/10.1029/96JA03637, 1997.

Arvelius, S., Yamauchi, M., Nilsson, H., Lundin, R., Hobara, Y., Rème, H., Bavassano-Cattaneo, M. B., Paschmann, G., Korth, A., Kistler, L. M., and Parks, G. K.: Statistics of high-altitude and high-latitude O+ ion outflows observed by Cluster/CIS, Ann. Geophys., 23, 1909-1916, https://doi.org/10.5194/angeo23-1909-2005, 2005.

Blanc, M., Horwitz, J. L., Blake, J. B., Daglis, I., Lemaire, J. F., Moldwin, M. B., Orsini, S., Thorne, R. M., and Wolfe, R. A.: Source and loss processes in the inner magnetosphere, Space Sci. Rev., 88, 137-206, https://doi.org/10.1023/A:1005203817354, 1999.

Buzulukova, N. Y., Galperin, Y. I., Kovrazhkin, R. A., Glazunov, A. L., Vladimirova, G. A., Stenuit, H., Sauvaud, J. A., and Delcourt, D. C.: Two types of ion spectral gaps in the quiet inner magnetosphere: Interball-2 observations and modeling, Ann. Geophys., 20, 349-364, https://doi.org/10.5194/angeo-20-349-2002, 2002.

Cattell, C., Johnson, L., Bergmann, R., Klumpar, D., Carlson, C., McFadden, J., Strangeway, R., Ergun, R., Sigsbee, K., and Pfaff, R.: FAST observations of discrete electrostatic waves in association with down-going ion beams in the auroral zone, J. Geophys. Res., 107, 1238, https://doi.org/10.1029/2001JA000254, 2002.

Chappell, C. R.: Recent satellite measurements of the morphology and dynamics of the plasmasphere, Rev. Geophys., 10, 951-979, https://doi.org/10.1029/RG010i004p00951, 1972.

Chappell, C. R., Olsen, R. C., Green, J. L., Johnson, J. F. E., and Waite Jr., J. H.: The discovery of nitrogen ions in the Earth's magnetosphere, Geophys. Res. Lett., 9, 937-940, https://doi.org/10.1029/GL009i009p00937, 1982. 
Chappell, C. R., Moore, T. E., and Waite, J. H.: The ionosphere as a fully adequate source of plasma for the Earth's magnetosphere, J. Geophys. Res., 92, 5896-5910, https://doi.org/10.1029/JA092iA06p05896, 1987.

Chappell, C. R., Huddleston, M. M., Moore, T. E., Giles, B. L., and Delcourt, D. C.: Observations of the warm plasma cloak and an explanation of its formation in the magnetosphere, J. Geophys. Res., 113, A09206, https://doi.org/10.1029/2007JA012945, 2008.

Claudepierre, S. G., Chen, M. W., Roeder, J. L., and Fennell, J. F.: An empirical model of ion plasma in the inner magnetosphere derived from CRRES/MICS measurements, J. Geophys. Res., 121, 11780-11797, https://doi.org/10.1002/2016JA023468, 2016.

Cladis, J. B.: Parallel acceleration and transport of ions from polar ionosphere to plasma sheet, Geophys. Res. Lett., 13, 893-896, https://doi.org/10.1029/GL013i009p00893, 1986.

Christon, S. P., Eastman, T. E., Doke, T., Frank, L. A., Gloeckler, G., Kojima, H., Kokubun, S., Lui, A. T. Y., Matsumoto, H., McEntire, R. W., Mukai, T., Nylund, S. R., Paterson, W. R., Roelof, E. C., Saito, Y., Sotirelis, T., Tsuruda, K., Williams, D. J., and Yamamoto, T.: Magnetospheric plasma regimes identified using Geotail measurements: 2. Statistics, spatial distribution, and geomagnetic dependence, J. Geophys. Res., 103, 23521-23542, https://doi.org/10.1029/98JA01914, 1998.

Collin, H. L., Quinn, J. M., and Cladis, J. B.: An empirical static model of low energy ring current ions, Geophys. Res. Lett., 20, 141-144, https://doi.org/10.1029/93GL00066, 1993.

Craven, P. D., Gallagher, D. L., and Comfort, R. H.: Relative concentration of $\mathrm{He}^{+}$in the inner magnetosphere as observed by the DE 1 retarding ion mass spectrometer, J. Geophys. Res., 102, 2279-2289, https://doi.org/10.1029/96JA02176, 1997.

Cully, C. M., Donovan, E. F., Yau, A. W., and Arkos, G. G.: Akebono/Suprathermal Mass Spectrometer observations of low-energy ion outflow: Dependence on magnetic activity and solar wind conditions, J. Geophys. Res., 108, 1093, https://doi.org/10.1029/2001JA009200, 2003.

Daglis, I. A., Thorne, R. M., Baumjohann, W., and Orsini, S.: The terrestrial ring current: Origin, formation, and decay, Rev. Geophys., 37, 407-438, https://doi.org/10.1029/1999RG900009, 1999.

Dandouras, I.: Detection of a plasmaspheric wind in the Earth's magnetosphere by the Cluster spacecraft, Ann. Geophys., 31, 1143-1153, https://doi.org/10.5194/angeo-31-1143-2013, 2013.

Dandouras, I., Yamauchi, M., and the ESCAPE proposal team: European SpaceCraft for the study of Atmospheric Particle Escape (ESCAPE), Mission proposals to 2016 ESA's call for M5 Mission, available at: http://cluster.irap.omp.eu/public/ ESCAPE/ESCAPE_M5_Proposal_V1.1.pdf (last access: 11 December 2019), 2016.

Dandouras, I., Yamauchi, M., De Keyser, J., Marghitu, O., Reme, H., Yoshikawa, I., Sakanoi, T., and the ESCAPE proposal team: ESCAPE: A mission proposal for ESA-M5 to systematically study Exosphere and atmospheric escape using European, Japanese, and US instruments, JAXA document SA6000118033, S10-001, available at: https://repository. exst.jaxa.jp/dspace/handle/a-is/876320 (last access: 11 December 2019), 2018 (in Japanese).

Darrouzet, F., De Keyser, J., Décréau, P. M. E., El LemdaniMazouz, F., and Vallières, X.: Statistical analysis of plasmas- pheric plumes with Cluster/WHISPER observations, Ann. Geophys., 26, 2403-2417, https://doi.org/10.5194/angeo-26-24032008, 2008.

Darrouzet, F., Gallagher, D. L., André, M., Carpenter, D. L., Dandouras, I., Décréau, P. M. E., De Keyser, J., Denton, R. E., Foster, J. C., Goldstein, J., Moldwin, M. B., Reinisch, B. W., Sandel, B. R., and Tu, J.: Plasmaspheric density structures and dynamics: Properties observed by the CLUSTER and IMAGE missions, Space Sci. Rev., 145, 55-106, https://doi.org/10.1007/s11214008-9438-9, 2009.

Dubinin, E., Fraenz, M., Woch, J., Barabash, S., Lundin, R., and Yamauchi, M.: Hydrogen exosphere at Mars: Pickup protons and their acceleration at the bow shock, Geophys. Res. Lett., 33, L22103, https://doi.org/10.1029/2006GL027799, 2006.

Dungey, J. W.: Interplanetary magnetic field and the auroral zones, Phys. Rev. Lett., 6, 47, https://doi.org/10.1103/PhysRevLett.6.47, 1961.

Ebihara, Y. and Ejiri, M.: Numerical Simulation of the Ring Current: Review, Space Sci. Rev., 105, 377-452, https://doi.org/10.1023/A:1023905607888, 2003.

Ebihara, Y., Yamauchi, M., Nilsson, H., Lundin, R., and Ejiri, M.: Wedge-like dispersion of sub-keV ions in the dayside magnetosphere: Particle simulation and Viking observation, J. Geophys. Res., 106, 29571-29584, https://doi.org/10.1029/2000JA000227, 2001.

Ebihara, Y., Ejiri, M., Nilsson, H., Sandahl, I., Grande, M., Fennell, J. F., Roeder, J. L., Weimer, D. R., and Fritz, T. A. Multiple discrete-energy ion features in the inner magnetosphere: 9 February 1998, event, Ann. Geophys., 22, 1297-1304, https://doi.org/10.5194/angeo-22-1297-2004, 2004.

Ebihara, Y., Kistler, L. M., and Eliasson, L.: Imaging cold ions in the plasma sheet from the Equator-S satellite, Geophys. Res. Lett., 35, L15103, https://doi.org/10.1029/2008GL034357, 2008.

Ejiri, M.: Trajectory traces of charged particles in the magnetosphere, J. Geophys. Res., 83, 4798-4810, https://doi.org/10.1029/JA083iA10p04798, 1978.

Ejiri, M., Hoffman, R. A., and Smith, P. H.: Energetic particle penetration into the inner magnetosphere, J. Geophys. Res., 85, 653663, https://doi.org/10.1029/JA085iA02p00653, 1980.

Eklund, U., Lundin, R., and Sandahl, I.: Measurements of $\mathrm{O}^{+}$in the high latitude magnetosheath, Phys. Chem. Earth, 22, 639-644, https://doi.org/10.1016/S0079-1946(97)00189-4, 1997.

Engwall, E., Eriksson, A. I., André, M., Dandouras, I., Paschmann, G., Quinn, J., and Torkar, K.: Low-energy (order $10 \mathrm{eV}$ ) ion flow in the magnetotail lobes inferred from spacecraft wake observations, Geophys. Res. Lett., 33, L06110, https://doi.org/10.1029/2005GL025179, 2006.

Engwall, E., Eriksson, A. I., Cully, C. M., André, M., Puhl-Quinn, P. A., Vaith, H., and Torbert, R.: Survey of cold ionospheric outflows in the magnetotail, Ann. Geophys., 27, 3185-3201, https://doi.org/10.5194/angeo-27-3185-2009, 2009.

Eliasson, L., André, M., Eriksson, A., Nordqvist, P., Norberg, O., Lundin, R., Holback, B., Koskinen, H., Borg, H., and Boehm, M.: Freja observations of heating and precipitation of positive ions, Geophys. Res. Lett., 21, 1911-1914, https://doi.org/10.1029/94GL01067, 1994.

European Space Agency: Cluster plotting software and data, Cluster Science Archive, available at: https://www.cosmos.esa.int/web/ csa/access (last access: 11 December 2019), 2013. 
Fok, M.-C., Kozyra, J. U., Nagy, A. F., and Cravens, T. E.: Lifetime of ring current particles due to coulomb collisions in the plasmasphere, J. Geophys. Res., 96, 7861-7867, https://doi.org/10.1029/90JA02620, 1991.

Fuselier, S. A., Burch, J. L., Mukherjee, J., Genestreti, K. J., Vines, S. K., Gomez, R., Goldstein, J., Trattner, K. J., Petrinec, S. M., Lavraud, B., and Strangeway, R. J.: Magnetospheric ion influence at the dayside magnetopause, J. Geophys. Res.-Space, 122, 8617-8631, https://doi.org/10.1002/2017JA024515, 2017.

Gallagher, D. L. and Comfort, R. H.: Unsolved problems in plasmasphere refilling, J. Geophys. Res.-Space, 121, 1447-1451, https://doi.org/10.1002/2015JA022279, 2016.

Giang, T. T., Hamrin, M., Yamauchi, M., Lundin, R., Nilsson, H., Ebihara, Y., Rème, H., Dandouras, I., Vallat, C., BavassanoCattaneo, M. B., Klecker, B., Korth, A., Kistler, L. M., and McCarthy, M.: Outflowing protons and heavy ions as a source for the sub-keV ring current, Ann. Geophys., 27, 839-849, https://doi.org/10.5194/angeo-27-839-2009, 2009.

Glocer, A., Toth, G., and Fok, M.-C.: Including kinetic ion effects in the coupled global ionospheric outflow solution, J. Geophys. Res., 123, 2851-2871, https://doi.org/10.1002/2018JA025241, 2018.

Goldstein, J.: Plasmasphere response: Tutorial and review of recent imaging results, Space Sci. Rev., 124, 203, https://doi.org/10.1007/s11214-006-9105-y, 2006.

Grünwaldt, H., Neugebauer, M., Hilchenbach, M., Bochsler, P., Hovestadt, D., Bürgi, A., Ipavich, F. M., Reiche, K.-U., Axford, W. I., Balsiger, H., Galvin, A. B., Geiss, J., Gliem, F., Gloeckler, G., Hsieh, K. C., Kallenbach, R., Klecker, B., Livi, S., Lee, M. A., Managadze, G. G., Marsch, E., Möbius, E., Scholer, M., Verigin, M. I., Wilken, B., and Wurz, P.: Venus tail ray observation near Earth, Geophys. Res. Lett., 24, 1163-1166, https://doi.org/10.1029/97GL01159, 1997.

Hamilton, D. C., Gloeckler, G., Ipavich, F. M., Studemann, W., Wilken, B., and Kremser, G.: Ring current development during the great geomagnetic storm of February 1986, J. Geophys. Res., 93, 14343-14355, https://doi.org/10.1029/JA093iA12p14343, 1988.

Harrison, J., Kaiser, A., and Vanden, J. M.: Atmospheric oxygen level and the evolution of insect body size, P. R. Soc. B, 277, 1937-1946, https://doi.org/10.1098/rspb.2010.0001, 2010.

Hill, S.: Influence of atmospheric oxygen concentration on acetylene reduction and efficiency of nitrogen fixation in intact Klebsiella pneumoniae, Microbiology, 93, 335-345, https://doi.org/10.1099/00221287-93-2-335, 1976.

Hirahara, M., Mukai, T., Terasawa, T., Machida, S., Saito, Y., Yamamoto, T., and Kokubun, S.: Cold dense ion flows with multiple components observed in the distant tail lobe by Geotail, J. Geophys. Res., 101, 7769-7784, https://doi.org/10.1029/95JA03165, 1996.

Hirahara, M., Mukai, T., Sagawa, E., Kaya, N., and Hayakawa, H.: Multiple energy-dispersed ion precipitations in low-latitude auroral oval: Evidence of $\boldsymbol{E} \times \boldsymbol{B}$ drift effect and up ward flowing ion contribution, J. Geophys. Res., 102, 2513-2530, https://doi.org/10.1029/96JA03148, 1997.

Hirahara, M., Seki, K., Saito, Y., and Mukai, T.: Periodic emergence of multicomposition cold ions modulated by geomagnetic field line oscillations in the near-Earth magnetosphere, J. Geophys.
Res., 109, A03211, https://doi.org/10.1029/2003JA010141, 2004.

Horwitz, J. L. and Chappell, C. R.: Observations of warm plasma in the dayside plasma trough at geosynchronous orbit, J. Geophys. Res., 84, 7075-7090, https://doi.org/10.1029/JA084iA12p07075, 1979.

Hultqvist, B.: Downward ion acceleration at auroral latitudes: cause of parallel electric field, Ann. Geophys., 20, 1117-1136, https://doi.org/10.5194/angeo-20-1117-2002, 2002.

Hultqvist, B., Aparicio, B., Borg, H., Arnoldy, R., and Moore, T. E.: Decrease of $\mathrm{keV}$ electron and ion fluxes in the dayside magnetosphere during the early phase of magnetospheric disturbances, Planet. Space Sci., 29, 107-126, https://doi.org/10.1016/00320633(81)90143-4, 1981.

Jakosky, B. M., Lin, R. P., Grebowsky, J. M., Luhmann, J. G., Mitchell, D. F., Beutelschies, G., Priser, T., Acuna, M., Andersson, L., Baird, D., Baker, D., Bartlett, R., Benna, M., Bougher, S., Brain, D., Carson, D., Cauffman, S., Chamberlin P., Chaufray, J.-Y., Cheatom, O., Clarke, J., Connerney, J., Cravens, T., Curtis, D., Delory, G., Demcak, S., DeWolfe, A., Eparvier, F., Ergun, R., Eriksson, A., Espley, J., Fang, X., Folta, D., Fox, J., GomezRosa, C., Habenicht, S., Halekas, J., Holsclaw, G., Houghton, M., Howard, R., Jarosz, M., Jedrich, N., Johnson, M., Kasprzak, W., Kelley, M., King, T., Lankton, M., Larson, D., Leblanc, F., Lefevre, F., Lillis, R., Mahaffy, P., Mazelle, C., McClintock, W., McFadden, J., Mitchell, D. L., Montmessin, F., Morrissey, J., Peterson, W., Possel, W., Sauvaud, J.-A., Schneider, N., Sidney, W., Sparacino, S., Stewart, A.I.F., Tolson, R., Toublanc, D., Waters, C., Woods, T., Yelle, R., and Zurek, R.: The Mars atmosphere and volatile evolution (MAVEN) mission, Space. Sci. Rev., 195, 3-48, https://doi.org/10.1007/s11214-015-0139-x, 2015.

Jordanova, V. K., Farrugia, C. J., Quinn, J. M., Torbert, R. B., Borovsky, J. E., Sheldon, R. B., and Peterson, W. K.: Simulation of off-equatorial ring current ion spectra measured by Polar for a moderate storm at solar minimum, J. Geophys. Res., 104, 429-436, https://doi.org/10.1029/98JA02658, 1999.

Kistler, L. M. and Mouikis, C. G.: The inner magnetosphere ion composi-tion and local time distribution over asolar cycle, J. Geophys. Res., 121, 2009-2032, https://doi.org/10.1002/2015JA021883, 2016.

Kistler, L. M., Mouikis, C., Möbius, E., Klecker, B., Sauvaud, J. A., Rème, H., Korth, A., Marcucci, M. F., Lundin, R., Parks, G. K., and Balogh, A.: Contribution of nonadiabatic ions to the cross-tail current in an $\mathrm{O}^{+}$dominated thin current sheet, J. Geophys. Res., 110, A06213, https://doi.org/10.1029/2004JA010653, 2005.

Kistler, L. M., Galvin, A. B., Popecki, M. A., Simunac, K. D. C., Farrugia, C., Moebius, E., Lee, M. A., Blush, L. M., Bochsler, P., Wurz, P., Klecker, B., Wimmer-Schweingruber, R. F., Opitz, A., Sauvaud, J.-A., Thompson, B., and Russell, C. T.: Escape of $\mathrm{O}^{+}$through the distant tail plasma sheet, Geophys. Res. Lett., 37, L21101, https://doi.org/10.1029/2010GL045075, 2010.

Kovrazhkin, R. A., Sauvaud, J.-A., and Delcourt, D. C.: INTERBALL-Auroral observations of $0.1-12 \mathrm{keV}$ ion gaps in the diffuse auroral zone, Ann. Geophys., 17, 734-742, https://doi.org/10.1007/s00585-999-0734-9, 1999.

Krauss, S., Fichtinger, B., Lammer, H., Hausleitner, W., Kulikov, Yu. N., Ribas, I., Shematovich, V. I., Bisikalo, D., Lichtenegger, H. I. M., Zaqarashvili, T. V., Khodachenko, M. L., 
and Hanslmeier, A.: Solar flares as proxy for the young Sun: satellite observed thermosphere response to an X17.2 flare of Earth's upper atmosphere, Ann. Geophys., 30, 1129-1141, https://doi.org/10.5194/angeo-30-1129-2012, 2012.

Kronberg, E. A., Ashour-Abdalla, M., Dandouras, I., and Delcourt, D. C.: Circulation of heavy ions and their dynamical effects in the magnetosphere: recent observations and models, Space Sci. Rev., 184, 173-235, https://doi.org/10.1007/s11214-014-0104-0, 2014.

Lakhina, G. S. and Tsurutani, B. T.: Satellite drag effects due to uplifted oxygen neutrals during super magnetic storms, Nonlin. Processes Geophys., 24, 745-750, https://doi.org/10.5194/npg24-745-2017, 2017.

Lennartsson, O. W.: ISEE ion composition data with implications for solar wind entry into Earth's magnetotail, Space Sci. Rev., 80, 305-323, https://doi.org/10.1023/A:1004982122553, 1997.

Lennartsson, O. W.: Ion composition aspects of magnetotail plasma flows, J. Geophys. Res., 106, 15621-15634, https://doi.org/10.1029/2000JA000427, 2001.

Lennartsson, O. W., Collin, H. L., and Peterson, W. K.: Solar wind control of Earth's $\mathrm{H}^{+}$and $\mathrm{O}^{+}$outflow rates in the $15 \mathrm{eV}$ to $33 \mathrm{keV}$ energy range, J. Geophys. Res., 109, A12212, https://doi.org/10.1029/2004JA010690, 2004.

Loesche, W. J.: Oxygen sensitivity of various anaerobic bacteria, Appl. Microbiol., 18, 723-727, 1969.

Lotko, W.: The magnetosphere-ionosphere system from the perspective of plasma circulation: A tutorial, J. Atmos. Sol.-Terr. Phy., 69, 191-211, https://doi.org/10.1016/j.jastp.2006.08.011, 2007.

Lundin, R.: Plasma composition and flow characteristics in the magnetospheric boundary layers connected to the polar cusp, in: The Polar Cusp, edited by: Holtet, J. A. and Egeland, A., 9-33, D. Reidel Publishing Comp., Dordrecht, 1985.

Lundin, R. and Guglielmi, A.: Ponderomotive forces in cosmos, Space Sci. Rev., 127, 1-116, https://doi.org/10.1007/s11214006-8314-8, 2006.

Lundin, R., Yamauchi, M., Woch, J., and Marklund, G.: Boundary layer polarization and voltage in the 14 MLT region, J. Geophys. Res., 100, 7587-7597, https://doi.org/10.1029/94JA02523, 1995.

Maezawa, K. and Hori, T.: The DistantMagnetotail: Its Structure, IMF Dependence and Thermal Properties, in: New Perspectives on the Earth's Magnetotail, edited by: Nishida, A., Baker, D. N., and Cowley, S. W. H., 1-19, AGU, https://doi.org/10.1029/GM105p0001, 1998.

Maggiolo, R. and Kistler, L. M.; Spatial variation in the plasma sheetcomposition: Dependence on geomag-netic and solar activity, J. Geophys. Res., 119, 2836-2857, https://doi.org/10.1002/2013JA019517, 2014.

Maggiolo, R.: Auroral arcs and ion outflow, in: Auroral Dynamics and Space Weather, edited by: Zhang, Y. and Paxton, L. J., 3958, AGU, https://doi.org/10.1002/9781118978719.ch4, 2015.

Marcucci, M. F., Bavassano-Cattaneo, M. B., Pallocchia, G., and Amata, E.: Energetic magnetospheric oxygen in the magnetosheath and its response to IMF orientation: Cluster observations, J. Geophys. Res., 109, A07203, https://doi.org/10.1029/2003JA010312, 2004.

Meier, R. R., Picone, J. M., Drob, D., Bishop, J., Emmert, J. T., Lean, J. L., Stephan, A. W., Strickland, D. J., Christensen, A. B., Paxton, L. J., Morrison, D., Wolven, Kil, H., Thomas,
B., Woods, N., Crowley, G., and Gibson, S. T.: Remote Sensing of Earth's Limb by TIMED/GUVI: Retrieval of thermospheric composition and temperature, Earth Space Sci., 2, 1-37, https://doi.org/10.1002/2014EA000035, 2015.

Moore, T. E. and Delcourt, D. C.: The geopause, Rev. Geophys., 33, 175-209, https://doi.org/10.1029/95RG00872, 1995.

Moore, T. E. and Horwitz, J. L.: Stellar ablation of planetary atmospheres, Rev. Geophys., 45, RG3002, https://doi.org/10.1029/2005RG000194, 2007.

Moore, T. E., Lundin, R., Alcayde, D., Andre, M., Ganguli, S. B., Temerin, M., and Yau, A.: Source processes in the high-latitute ionosphere, Space Sci. Rev., 88, 7-84, https://doi.org/10.1023/A:1005299616446, 1999a.

Moore, T. E., Peterson, W. K., Russell, C. T., Chandler, M. O., Collier, M. R., Collin, H. L., Craven, P. D., Fitzenreiter, R., Giles, B. L., and Pollock, C. J.: Ionospheric mass ejection in response to a CME, Geophys. Res. Lett., 26, 2339-2342, https://doi.org/10.1029/1999GL900456, 1999b.

Moore, T. E., Fok, M.-C., and Garcia-Sage, K.: The ionospheric outflow feedback loop, J. Atmos. Sol.-Terr. Phy., 115-116, 5966, https://doi.org/10.1016/j.jastp.2014.02.002, 2014.

Möbius, E., Tang, L., Kistler, L. M., and Popecki, M.: Species dependent energies in upward directed ion beams over auroral arcs as observed with FAST TEAMS, Geophys. Res. Lett., 25, 2029 2032, https://doi.org/10.1029/98GL00381, 1998.

Newell, P. T. and Meng, C. I.: Substorm introduction of $1 \mathrm{keV}$ magnetospheric ions into the inner plasmasphere, J. Geophys. Res., 91, 11133-11145, https://doi.org/10.1029/JA091iA10p11133, 1986.

Newell, P. T., Sotirelis, T., and Wing, S.: Seasonal variations in diffuse, monoenergetic, and broadband aurora, J. Geophys. Res. 115, A03216, https://doi.org/10.1029/2009JA014805, 2010.

Nilsson, H., Waara, M., Arvelius, S., Marghitu, O., Bouhram, M., Hobara, Y., Yamauchi, M., Lundin, R., Rème, H., Sauvaud, J.-A., Dandouras, I., Balogh, A., Kistler, L. M., Klecker, B., Carlson, C. W., Bavassano-Cattaneo, M. B., and Korth, A.: Characteristics of high altitude oxygen ion energization and outflow as observed by Cluster: a statistical study, Ann. Geophys., 24, 1099-1112, https://doi.org/10.5194/angeo-24-1099-2006, 2006.

Nilsson, H., Barghouthi, I. A., Slapak, R., Eriksson, A., and André, M.: Hot and cold ion outflow: spatial distribution of ion heating, J. Geophys. Res., 117, A11201, https://doi.org/10.1029/2012JA017974, 2012.

Nilsson, H., Hamrin, M., Pitkänen, T., Karlsson, T., Slapak, R., Andersson, L., Gunell, H., Schillings, A., and Vaivads, A.: Oxygen ion response to proton bursty bulk flows, J. Geophys. Res., 121, 7535-7546, https://doi.org/10.1002/2016JA022498, 2016.

Norqvist, P., André, M., Eliasson, L., Eriksson, A. I., Blomberg, L., Lühr, H., and Clemmons, J. H.: Ion cyclotron heating in the dayside magnetosphere, J. Geophys. Res., 101, 13179-13193, https://doi.org/10.1029/95JA03596, 1996.

Norqvist, P., Andre, M., and Tyrland, M.: A statistical study of ion energization mechanisms in the auroral region, J. Geophys. Res. 103, 23459-23474, https://doi.org/10.1029/98JA02076, 1998.

Nosé, M., Ieda, A., and Christon, S. P.: Geotail observations of plasma sheet ion composition over 16 years: On variations of average plasma ion mass and $\mathrm{O}^{+}$triggering substorm model, J. Geophys. Res., 114, A07223, https://doi.org/10.1029/2009JA014203, 2009. 
Ohtani, S., Potemra, T. A., Newell, P. T., Zanetti, L. J., Iijima, T., Watanabe, M., Yamauchi, M., Elphinstone, R. D., de la Beaujardiere, O., and Blomberg, L. G.: Simultaneous prenoon and postnoon observations of three field-aligned current systems from Viking and DMSP-F7, J. Geophys. Res., 100, 119-136, https://doi.org/10.1029/94JA02073, 1995.

Ohtani, S., Shay, M. A., and Mukai, T.: Temporal structure of the fast convective flow in the plasma sheet: Comparison between observations and two-fluid simulations, J. Geophys. Res., 109, A03210, https://doi.org/10.1029/2003JA010002, 2004.

Olsen, R. C.: The density minimum at the Earth's magnetic equator, J. Geophys. Res., 97, 1135-1150, https://doi.org/10.1029/91JA02719, 1992.

Olsen, R. C., Shawhan, S. D., Gallagher, D. L., Green, J. L., Chappell, C. R., and Anderson, R. R.: Plasma observations at the Earth's magnetic equator, J. Geophys. Res., 92, 2385-2407, https://doi.org/10.1029/JA092iA03p02385, 1987.

Øieroset, M., Yamauchi, M., Liszka, L., and Christon, S. P.: Energetic ion outflow from the dayside ionosphere and its relationship to the interplanetary magnetic field and substorm activity, J. Atmos. Sol.-Terr. Phy., 62, 485-493, https://doi.org/10.1016/S1364-6826(00)00016-X, 2000.

Opitz, A., Sauvaud, J.-A., Klassen, A., Gomez-Herrero, R., Bucik, R., Kistler, L. M., Jacquey, C., Luhmann, J., Glenn Mason, G., Primoz Kajdic, P., and Lavraud, B.: Solar wind control of the terrestrial magnetotail as seen by STEREO, J. Geophys. Res., 119, 6342-6355, https://doi.org/10.1002/2014JA019988, 2014.

Park, C. G.: Some features of plasma distribution in plasmasphere deduced from antarctic whistlers, J. Geophys. Res., 79, 169-173, https://doi.org/10.1029/JA079i001p00169, 1974.

Peterson, W. K., Collin, H. L., Yau, A. W., and Lennartsson, O. W.: Polar/TIMAS observations of suprathermal ion outflow during solar minimum conditions, J. Geophys. Res., 106, 6059, https://doi.org/10.1029/2000JA003006, 2001.

Peterson, W. K., Collin, H. L., Lennartsson, O. W., and Yau, A. W.: Quiet time solar illumination effects on the fluxes and characteristic energies of ionospheric outflow, J. Geophys. Res., 111, A11S05, https://doi.org/10.1029/2005JA011596, 2006.

Peterson, W. K., Andersson, L., Callahan, B. C., Collin, H. L., Scudder, J. D., and Yau, A. W.: Solar-minimum quiet time ion energization and outflow in dynamic boundary related coordinates, J. Geophys. Res., 113, A07222, https://doi.org/10.1029/2008JA013059, 2008.

Potemra, T. A.: Sources of large-scale Birkeland currents, in: Physical signatures of magnetospheric boundary layer process, edited by: Holtet, J. A. and Egeland, A., 3-27, Kluwer Academic Publishers, Dordrecht, the Netherlands, 1994.

Pollock, C. J., Chandler, M. O., Moore, T. E., Waite, J. H., Chappell, C. R., and Gurnett, D. A.: A survey of upwelling ion event characteristics, J. Geophys. Res., 95, 18969-18980, https://doi.org/10.1029/JA095iA11p18969, 1990.

Quinn, J. M. and Mcllwain, C. E.: Bouncing ion clusters in the Earth's magnetosphere, J. Geophys. Res., 84, 7365-7370, https://doi.org/10.1029/JA084iA12p07365, 1979.

Rème, H., Aoustin, C., Bosqued, J. M., Dandouras, I., Lavraud, B., Sauvaud, J. A., Barthe, A., Bouyssou, J., Camus, Th., Coeur-Joly, O., Cros, A., Cuvilo, J., Ducay, F., Garbarowitz, Y., Medale, J. L., Penou, E., Perrier, H., Romefort, D., Rouzaud, J., Vallat, C., Alcaydé, D., Jacquey, C., Mazelle, C., d'Uston, C., Möbius, E.,
Kistler, L. M., Crocker, K., Granoff, M., Mouikis, C., Popecki, M., Vosbury, M., Klecker, B., Hovestadt, D., Kucharek, H., Kuenneth, E., Paschmann, G., Scholer, M., Sckopke, N., Seidenschwang, E., Carlson, C. W., Curtis, D. W., Ingraham, C., Lin, R. P., McFadden, J. P., Parks, G. K., Phan, T., Formisano, V., Amata, E., Bavassano-Cattaneo, M. B., Baldetti, P., Bruno, R., Chionchio, G., Di Lellis, A., Marcucci, M. F., Pallocchia, G., Korth, A., Daly, P. W., Graeve, B., Rosenbauer, H., Vasyliunas, V., McCarthy, M., Wilber, M., Eliasson, L., Lundin, R., Olsen, S., Shelley, E. G., Fuselier, S., Ghielmetti, A. G., Lennartsson, W., Escoubet, C. P., Balsiger, H., Friedel, R., Cao, J.-B., Kovrazhkin, R. A., Papamastorakis, I., Pellat, R., Scudder, J., and Sonnerup, B.: First multispacecraft ion measurements in and near the Earth's magnetosphere with the identical Cluster ion spectrometry (CIS) experiment, Ann. Geophys., 19, 1303-1354, https://doi.org/10.5194/angeo-19-1303-2001, 2001.

Ribas, S., Guinan, E. F., Güdel, M., and Audard, M.: Evolution of the solar activity over time and effects on planetary atmospheres. I. High-energy irradiances (1-1700 ̊), Astrophys. J., 622, 680694, https://doi.org/10.1086/427977, 2005.

Sandel, B. R.: Composition of the plasmasphereand implications for refilling, Geophys. Res. Lett., 38, L14104, https://doi.org/10.1029/2011GL048022, 2011.

Sandel, B. R. and Denton, M. H.: Global view of refilling of the plasmasphere, Geophys. Res. Lett., 34, L17102, https://doi.org/10.1029/2007GL030669, 2007.

Sandhu, J. K., Yeoman, T. K., Fear, R. C., and Dandouras, I.: A statistical study of magnetospheric ion composition along the geomagnetic field using the Cluster spacecraft for $\mathrm{L}$ values between 5.9 and 9.5, J. Geophys. Res., 121, 2194-2208, https://doi.org/10.1002/2015JA022261, 2016.

Sauvaud, J.-A., Crasnier, J., Mouala, K., Kovrazhkin, R. A., and Jorjio, N. V.: Morning sector ion precipitation following substorm injections, J. Geophys. Res., 86, 3430-3438, https://doi.org/10.1029/JA086iA05p03430, 1981.

Sauvaud, J.-A., Popescu, D., Delcourt, D. C., Parks, G. K., Brittnacher, M., Sergeev, V., Kovrazhkin, R. A., Mukai, T., and Kokubun, S.: Sporadic plasma sheet ion injections into the highaltitude auroral bulge: Satellite observations, J. Geophys. Res., 104, 28565-28586, https://doi.org/10.1029/1999JA900293, 1999.

Sauvaud, J.-A., Lundin, R., Rème, H., McFadden, J. P., Carlson, C., Parks, G. K., Möbius, E., Kistler, L. M., Klecker, B., Amata, E., DiLellis, A. M., Formisano, V., Bosqued, J. M., Dandouras, I., Décréau, P., Dunlop, M., Eliasson, L., Korth, A., Lavraud, B., and McCarthy, M.: Intermittent thermal plasma acceleration linked to sporadic motions of the magnetopause, first Cluster results, Ann. Geophys., 19, 1523-1532, https://doi.org/10.5194/angeo19-1523-2001, 2001.

Sauvaud, J.-A., Louarn, P., Fruit, G., Stenuit, H., Vallat, C., Dandouras, I., Rème, H., André, M., Balogh, A., Dunlop, M., Kistler, L., Möbius, E., Mouikis, C., Klecker, B., Parks, G. K., McFadden, J., Carlson, C., Marcucci, F., Pallocchia, G., Lundin, R., Korth, A., and McCarthy, M.: Case studies of the dynamics of ionospheric ions in the Earth's magnetotail, J. Geophys. Res., 109, A01212, https://doi.org/10.1029/2003JA009996, 2004.

Schillings, A., Nilsson, H., Slapak, R., Yamauchi, M., and Westerberg, L.-G.: Relative outflow enhancements during major ge- 
omagnetic storms - Cluster observations, Ann. Geophys., 35, 1341-1352, https://doi.org/10.5194/angeo-35-1341-2017, 2017.

Schillings, A., Slapak, R., Nilsson, N., Yamauchi, M., Dandouras, I., and Westerberg, L.-G.: Earth atmospheric loss through the plasma mantle and its dependence on solar wind parameters, Earth Planet Space, 71, 70, https://doi.org/10.1186/s40623-0191048-0, 2019.

Seki, K., Elphic, R. C., Hirahara, M., Terasawa, T., and Mukai, T.: On atmospheric loss of oxygen ions from Earth through magnetospheric processes, Science, 291, 1939-1941, https://doi.org/10.1126/science.1058913, 2001.

Seki, K., Hirahara, M., Hoshino, M., Terasawa, T., Elphic, R. C., Saitok, Y., Mukaik, T., Hayakawak, H., Kojima, H., and Matsumoto, H.: Cold ions in the hot plasma sheet of Earth's magnetotail, Nature, 422, 589-592, https://doi.org/10.1038/nature01502, 2003.

Sergeev, V. A., Malkov, M., and Mursula, K.: Testing the isotropic boundary algorithm method to evaluate the magnetic field configuration in the tail, J. Geophys. Res., 98, 7609-7620, https://doi.org/10.1029/92JA02587, 1993.

Shelley, E. G., Johnson, R. G., and Sharp, R. D.: Satellite observations of energetic heavy ions during a geomagnetic storm, J. Geophys. Res., 77, 6104-6110, https://doi.org/10.1029/JA077i031p06104, 1972.

Sibeck, D. G., McEntire, R. W., Lui, A. T. Y., Lopez, R. E., Krimigis, S. M., Decker, R. B., Zanetti, L. J., and Potemra, T. A.: Energetic magnetospheric ions at the dayside magnetopause: Leakage or merging?, J. Geophys. Res., 92, 1209712114, https://doi.org/10.1029/JA092iA11p12097, 1987.

Sibeck, D. G., Paschmann, G., Treumann, R. A., Fuselier, S. A., Lennartsson, W., Lockwood, M., Lundin, R., Ogilvie, K. W., Onsager, T. G., Phan, T.-D., Roth, M., Scholer, M., Sckopke, N., Stasiewicz, K., and Yamauchi, M.: Plasma transfer processes at the magnetopause, Space Sci. Rev., 88, 207-283, https://doi.org/10.1023/A:1005255801425, 1999.

Singh, N. and Horwitz, J. L.: Plasmasphere refilling: Recent observations and modeling, J. Geophys. Res., 97, 1049-1079, https://doi.org/10.1029/91JA02602, 1992.

Slapak, R. and Nilsson, H.: The oxygen ion circulation in the outer terrestrial magnetosphere and its dependence on geomagnetic activity, Geophys. Res. Lett., 45, 12669-12676, https://doi.org/10.1029/2018GL079816, 2018.

Slapak, R., Nilsson, H., and Westerberg, L. G.: A statistical study on $\mathrm{O}^{+}$flux in the dayside magnetosheath, Ann. Geophys., 31, 1005-1010, https://doi.org/10.5194/angeo-31-1005-2013, 2013.

Slapak, R., Schillings, A., Nilsson, H., Yamauchi, M., Westerberg, L.-G., and Dandouras, I.: Atmospheric loss from the dayside open polar region and its dependence on geomagnetic activity: implications for atmospheric escape on evolutionary timescales, Ann. Geophys., 35, 721-731, https://doi.org/10.5194/angeo-35721-2017, 2017a.

Slapak, R., Hamrin, M., Pitkänen, T., Yamauchi, M., Nilsson, H., Karlsson, T., and Schillings, A.: Quantification of the total ion transport in the near-Earth plasma sheet, Ann. Geophys., 35, 869-877, https://doi.org/10.5194/angeo-35-869-2017, 2017 b.

Sonnerup, B. U.: Magnetopause reconnection rate, J. Geophys. Res., 79, 1546-1549, https://doi.org/10.1029/JA079i010p01546, 1974.
Strangeway, R. J., Ergun, R. E., Su, Y.-J., Carlson, C. W., and Elphic, R. C.: Factors controlling ionospheric outflows as observed at intermediate altitudes, J. Geophys. Res., 110, A03221, https://doi.org/10.1029/2004JA010829, 2005.

Su, Y. J., Horwitz, J. L., Moore, T. E., Giles, B. L., Chandler, M. O., Craven, P. D., Hirahara, M., and Pollock, C. J.: Polar wind survey with the Thermal Ion Dynamics Experiment/Plasma Source Instrument suite aboard POLAR, J. Geophys. Res., 103, 2930529337, https://doi.org/10.1029/98JA02662, 1998.

Tian, F., Kasting, J. F., Liu, H.-L., and Roble, R. G.: Hydrodynamic planetary thermosphere model: 1 . Response of the Earth's thermosphere to extreme solar EUV conditions and the significance of adiabatic cooling, J. Geophys. Res., 113, E05008, https://doi.org/10.1029/2007JE002946, 2008.

Toledo-Redondo, S., André, M., Vaivads, A., Khotyaintsev, Y. V., Lavraud, B., Graham, D. B., Divin, A., and Aunai, N.: Cold ion heating at the dayside magnetopause during magnetic reconnection, Geophys. Res. Lett., 43, 58-66, https://doi.org/10.1002/2015GL067187, 2016.

Vasyliunas, V. M.: Multiple-branch model of the open magnetopause, Geophys. Res. Lett., 22, 1145-1147, https://doi.org/10.1029/95GL01068, 1995.

Vallat, C., Ganushkina, N., Dandouras, I., Escoubet, C. P., Taylor, M. G. G. T., Laakso, H., Masson, A., Sauvaud, J.-A., Rème, H., and Daly, P.: Ion multi-nose structures observed by Cluster in the inner Magnetosphere, Ann. Geophys., 25, 171-190, https://doi.org/10.5194/angeo-25-171-2007, 2007.

Waara, M., Slapak, R., Nilsson, H., Stenberg, G., André, M., and Barghouthi, I. A.: Statistical evidence for $\mathrm{O}^{+}$energization and outflow caused by wave-particle interaction in the high altitude cusp and mantle, Ann. Geophys., 29, 945-954, https://doi.org/10.5194/angeo-29-945-2011, 2011.

Walker, R., Terasawa, T., Christon, S. P., Angelopoulos, V., Hoshino, M., Lennartsson, W., Maezawa, K., Sibeck, D. G., Treumann, R. A., Williams, D. J., and Zelenyi, L.: Source and loss processes in the magnetotail, Space Sci. Rev., 88, 285-353, https://doi.org/10.1023/A:1005207918263, 1999.

Waite, J. H., Gallagher, D. L., Chandler, M. O., Olsen, R. C., Comfort, R. H., Johnson, J. F. E., Chappell, C. R., Peterson, W. K., Weimer, D., and Shawhan, S. D.: Plasma and field observations of a Pc5 wave event, J. Geophys. Res., 91, 11147-11161, https://doi.org/10.1029/JA091iA10p11147, 1986.

Watanabe, S., Whalen, B. A., and Yau, A. W.: Thermal ion observations of depletion and refilling in the plasmaspheric trough, J. Geophys. Res., 97, 1081-1096, https://doi.org/10.1029/91JA02818, 1992.

Welling, D. T., Jordanova, V. K., Zaharia, S. G., Glocer, A., and Toth, G.: The effects of dynamic ionospheric outflow on the ring current, J. Geophys. Res., 116, A00J19, https://doi.org/10.1029/2010JA015642, 2011.

Welling, D. T., André, M., Dandouras, I., Delcourt, D., Fazakerley, A., Fontaine, D., Foster, J., Ilie, R., Kistler, L., Lee, J. H., Liemohn, M. W., Slavin, J. A., Wang, C.-P., Wiltberger, M., and Yau, A.: The Earth: plasma sources, losses, and transport processes, Space. Sci. Rev., 192, 145, https://doi.org/10.1007/s11214-015-0187-2, 2015.

Winglee, R. M., Chua, D., Brittnacher, M., Parks, G. K., and Lu, G.: Global impact of ionospheric outflows on the dynamics of the 
magnetosphere and cross-polar cap potential, J. Geophys. Res., 107, 1237, https://doi.org/10.1029/2001JA000214, 2002.

Winningham, D. J., Yasuhara, F., Akasofu, S.-I., and Heikkila, W. J.: The latitudinal morphology of $10 \mathrm{eV}$ to $10 \mathrm{keV}$ electron fluxes during quiet and disturbed times in the 2100-0300 MLT sector, J. Geophys. Res., 80, 3148-3171, https://doi.org/10.1029/JA080i022p03148, 1975.

Woch, J. and Lundin, R.: The low-latitude boundary layer at mid-altitudes: Identification based on Viking hot plasma data, Geophys. Res. Lett., 20, 979-982, https://doi.org/10.1029/93GL00849, 1993.

Wood, B. E.: The solar wind and the Sun in the past, Space Sci. Rev., 126, 3-14, https://doi.org/10.1007/s11214-006-9006-0, 2006.

Yamauchi, M. and Lundin, R.: The wave-assisted cusp model: Comparison to low-altitude observations, Phys. Chem. Earth, 22, 729-734, https://doi.org/10.1016/S0079-1946(97)00203-6, 1997.

Yamauchi, M. and Lundin, R.: Sub-keV ring current ions as the tracer of substorm injection, Ann. Geophys., 24, 355-366, https://doi.org/10.5194/angeo-24-355-2006, 2006.

Yamauchi, M. and Slapak, R.: Cusp current system: an energy source view, in: Electric Currents in Geospace and Beyond, edited by: Keiling, A., Marghitu, O., and Wheatland, M., 339-358, American Geophysical Union, Washington, DC., https://doi.org/10.1002/9781119324522.ch20, 2018a.

Yamauchi, M. and Slapak, R.: Energy conversion through mass loading of escaping ionospheric ions for different $\mathrm{Kp}$ values, Ann. Geophys., 36, 1-12, https://doi.org/10.5194/angeo-36-12018, 2018b.

Yamauchi, M. and Wahlund, J.-E.: Role of the ionosphere for the atmospheric evolution of planets, Astrobiology J., 7, 783-800, https://doi.org/10.1089/ast.2007.0140, 2007.

Yamauchi, M., Lundin, R., Mursula, K., Marklund, G., and Potemra, T. A.: Dayside Pc5 pulsation detected by Viking ion data at $L=4$, Geophys. Res. Lett., 23, 2517-2520, https://doi.org/10.1029/96GL02140, 1996.

Yamauchi, M., Lundin, R., Eliasson, L., Winningham, D., Reme, H., Vallat, C., Dandouras, I., and Cluster-CIS team: Structures of sub-keV ions inside the ring current region, in: The Inner Magnetosphere: Physics and Modeling, edited by: Pulkkinen, T. I., Tsyganenko, N. A., and Friedel, R., 41-46, American Geophysical Union, Washington, DC., https://doi.org/10.1029/155GM05, 2005a.

Yamauchi, M., Eliasson, L., Lundin, R., and Norberg, O.: Unusual heavy ion injection events observed by Freja, Ann. Geophys., 23, 535-543, https://doi.org/10.5194/angeo-23-535-2005, 2005 b.

Yamauchi, M., Brandt, P. C., Ebihara, Y., Dandouras, I., Nilsson, H., Lundin, R., Rème, H., Vallat, C., Lindquvist, P.-A., Balogh, A., and Daly, P. W.: Source location of the wedge-like dispersed ring current in the morning sector during a substorm, J. Geophys. Res., 111, A11S09, https://doi.org/10.1029/2006JA011621, 2006a.

Yamauchi, M., Iyemori, Y., Frey, H., and Henderson, M.: Unusually quick development of a $4000 \mathrm{nT}$ substorm during the initial 10 min of the 29 October 2003 magnetic storm, J. Geophys. Res., 111, A04217, https://doi.org/10.1029/2005JA011285, 2006b.

Yamauchi, M., Ebihara, Y., Dandouras, I., and Rème, H.: Dual source populations of substorm-associated ring current ions,
Ann. Geophys., 27, 1431-1438, https://doi.org/10.5194/angeo27-1431-2009, 2009a.

Yamauchi, M., Dandouras, I., Daly, P. W., Stenberg, G., Frey, H. U., Lindqvist, P.-A., Ebihara, Y., Nilsson, H., Lundin, R., Rème, H., André, M., Kronberg, E. A., Balogh, A., and Henderson, M.: Magnetospheric solitary structure maintained by $3000 \mathrm{~km} / \mathrm{s}$ ions as a cause of westward moving auroral bulge at 19MLT, Ann. Geophys., 27, 2947-2969, https://doi.org/10.5194/angeo27-2947-2009, 2009b.

Yamauchi, M., Dandouras, I., Rème, H., and El-Lemdani Mazouz, F.: Equatorially confined warm trapped ions at around $100 \mathrm{eV}$ near the plasmapause, Geophys. Res. Lett., 39, L15101, https://doi.org/10.1029/2012GL052366, 2012.

Yamauchi, M., Dandouras, I., Rème, H., Lundin, R., and Kistler, L. M.: Cluster observation of few-hour-scale evolution of structured plasma in the inner magnetosphere, Ann. Geophys., 31, 15691578, https://doi.org/10.5194/angeo-31-1569-2013, 2013.

Yamauchi, M., Dandouras, I., Rème, H., and Nilsson, H.: Cluster observations of hot $\mathrm{He}^{+}$events in the inner magnetosphere, J. Geophys. Res., 119, 2706-2716, https://doi.org/10.1002/2013JA019724, 2014a.

Yamauchi, M., Ebihara, Y., Nilsson, H., and Dandouras, I.: Ion drift simulation of sudden appearance of sub-keV structured ions in the inner magnetosphere, Ann. Geophys., 32, 83-90, https://doi.org/10.5194/angeo-32-83-2014, 2014b.

Yamauchi, M., Hara, T., Lundin, R., Dubinin, E., Fedorov, A., Sauvaud, J.-A., Frahm, R. A., Ramstad, R., Futaana, Y., Holmström, M., and Barabash, S.: Seasonal variation of Martian pickup ions: evidence of breathing exosphere, Planet. Space Sci., 119, 54-61, https://doi.org/10.1016/j.pss.2015.09.013, 2015.

Yamauchi, M., Sergienko, T., Enell, C.-F., Schillings, A., Slapak, R., Johnsen, M. G., Tjulin, A., and Nilsson, H.: Ionospheric response observed by EISCAT during the September 6-8, 2017, space weather event: overview, Space Weather, 16, 1437-1450, https://doi.org/10.1029/2018SW001937, 2018.

Yau, A. W. and Whalen, B. A.: Auroral ion composition during large magnetic storms, Can. J. Phys., 70, 500-509, https://doi.org/10.1139/p92-085, 1992.

Yau, A. W., Abe, T., and Peterson, W. K.: The polar wind: Recent observations, J. Atmos. Sol.-Terr. Phy., 69, 1936-1983, https://doi.org/10.1016/j.jastp.2007.08.010, 2007.

Zong, Q.-G., Zhou, X.-Z., Wang, Y. F., Li, X., Song, P., Baker, D. N., Fritz, T. A., Daly, P. W., Dunlop, M., and Pedersen, A.: Energetic electron response to ULF waves induced by interplanetary shocks in the outer radiation belt, J. Geophys. Res., 114, A10204, https://doi.org/10.1029/2009JA014393, 2009.

Zoennchen, J. H., Nass, U., and Fahr, H. J.: Terrestrial exospheric hydrogen density distributions under solar minimum and solar maximum conditions observed by the TWINS stereo mission, Ann. Geophys., 33, 413-426, https://doi.org/10.5194/angeo-33413-2015, 2015.

Zoennchen, J. H., Nass, U., Fahr, H. J., and Goldstein, J.: The response of the $\mathrm{H}$ geocorona between 3 and $8 R_{\mathrm{e}}$ to geomagnetic disturbances studied using TWINS stereo Lyman- $\alpha$ data, Ann. Geophys., 35, 171-179, https://doi.org/10.5194/angeo-35171-2017, 2017. 